This item was submitted to Loughborough's Research Repository by the author.

Items in Figshare are protected by copyright, with all rights reserved, unless otherwise indicated.

\title{
An analytical approach for prediction of elastohydrodynamic friction with inlet shear heating and starvation
}

PLEASE CITE THE PUBLISHED VERSION

http://dx.doi.org/10.1007/s11249-016-0740-5

\section{PUBLISHER}

(c) The Authors. Published by Springer Verlag (Germany)

\section{VERSION}

VoR (Version of Record)

\section{PUBLISHER STATEMENT}

This work is made available according to the conditions of the Creative Commons Attribution 4.0 International (CC BY 4.0) licence. Full details of this licence are available at: http://creativecommons.org/licenses/ by/4.0/

\section{LICENCE}

CC BY 4.0

\section{REPOSITORY RECORD}

Paouris, Leonidas, Ramin Rahmani, Stephanos Theodossiades, Homer Rahnejat, Gregory Hunt, and William Barton. 2019. "An Analytical Approach for Prediction of Elastohydrodynamic Friction with Inlet Shear Heating and Starvation". figshare. https://hdl.handle.net/2134/22580. 


\title{
An Analytical Approach for Prediction of Elastohydrodynamic Friction with Inlet Shear Heating and Starvation
}

\author{
L. Paouris ${ }^{1} \cdot$ R. Rahmani1 ${ }^{1}$ (D) S. Theodossiades ${ }^{1} \cdot$ H. Rahnejat ${ }^{1}$ - G. Hunt ${ }^{2}$ • \\ W. Barton ${ }^{2}$
}

Received: 20 April 2016/ Accepted: 17 August 2016

(c) The Author(s) 2016. This article is published with open access at Springerlink.com

\begin{abstract}
An analytical friction model is presented, predicting the coefficient of friction in elastohydrodynamic (EHD) contacts. Three fully formulated SAE 75W-90 axle lubricants are examined. The effect of inlet shear heating (ISH) and starvation is accounted for in the developed friction model. The film thickness and the predicted friction are compared with experimental measurements obtained through optical interferometry and use of a mini traction machine. The results indicate the significant contribution of ISH and starvation on both the film thickness and coefficient of friction. A strong interaction between those two phenomena is also demonstrated, along with their individual and combined contribution on the EHD friction.
\end{abstract}

Keywords Elastohydrodynamic lubrication - Inlet shear heating $\cdot$ Starvation $\cdot$ Lubricant rheology

$\begin{array}{ll}\text { Abbreviations } \\ \text { EHD } & \text { Elastohydrodynamic } \\ \text { ISH } & \text { Inlet shear heating } \\ \text { LSS } & \text { Limiting shear stress } \\ \text { MTM } & \text { Mini traction machine } \\ \text { PAO } & \text { Polyalphaolefin } \\ \text { PV } & \text { Pressure-viscosity } \\ \text { SRR } & \text { Slide-roll ratio }\end{array}$

R. Rahmani

r.rahmani@lboro.ac.uk

1 Wolfson School of Mechanical and Manufacturing Engineering, Loughborough University, Loughborough, Leicestershire LE11 3TU, UK

2 Applied Sciences Department, Lubrizol Ltd, Hazelwood, Derby, Derbyshire DE56 4AN, UK
SAE Society of Automotive Engineers

TEHD Thermo-elastohydrodynamic

VM Viscosity modifier

\section{List of symbols}

$A_{1} \quad$ Temperature-viscosity coefficient (-)

$A_{\text {EHL }} \quad$ EHD contact footprint area $\left(\mathrm{m}^{2}\right)$

$a_{\mathrm{h}} \quad$ Heat partitioning coefficient (-)

$a_{\text {TTS }} \quad$ TTS shifting coefficient (-)

$c_{s} \quad$ Heat capacity of the solid bodies (steel, glass) $\left(\mathrm{J} / \mathrm{kg}^{\circ} \mathrm{C}\right)$

$c_{p, f} \quad$ Heat capacity of the lubricant at constant pressure $\left(\mathrm{J} / \mathrm{kg}^{\circ} \mathrm{C}\right)$

$E^{\prime} \quad$ Reduced Young's modulus of elasticity of contacting bodies $(\mathrm{Pa})$

$E_{\mathrm{b}} \quad$ Young's modulus of elasticity of the steel ball (Pa)

$E_{\mathrm{d}} \quad$ Young's modulus of elasticity of the disc (steel or glass) $(\mathrm{Pa})$

$G \quad$ Chittenden-Dowson dimensionless material parameter (-)

$h_{\mathrm{c}} \quad$ EHD central film thickness (m)

$h_{\mathrm{c}, \text { ISH }}$ Reduced central film thickness due to ISH Gupta [39] (m)

$h_{\mathrm{c}, \text { iso }} \quad$ Isothermal central film thickness (m)

$h_{i} \quad$ Film thickness at the centre of the EHD conjunction (m)

$k_{f} \quad$ Thermal conductivity of the lubricant $(\mathrm{W} / \mathrm{m} \mathrm{K})$

$k_{s} \quad$ Thermal conductivity of the solid bodies (steel, glass) $(\mathrm{W} / \mathrm{m} \mathrm{K})$

$L \quad$ Gupta's [39] thermal loading parameter (-)

$p \quad$ Contact pressures $(\mathrm{Pa})$

$\bar{p} \quad$ Average Hertzian pressure $(\mathrm{Pa})$

$p_{\mathrm{a}} \quad$ Ambient pressure $(\mathrm{Pa})$

$p_{\mathrm{h}} \quad$ Maximum Hertzian pressure $(\mathrm{Pa})$ 
$p_{\mathrm{i}} \quad$ Inlet pressure of the lubricant $(\mathrm{Pa})$

$\dot{q} \quad$ Heat generation rate in the central region of the EHD conjunction (W)

$q^{k} \quad$ Parameter value for the $k$ th iteration

$r \quad$ Radial distance from the centre of the circular contact footprint $(\mathrm{m})$

$R_{\mathrm{b}} \quad$ Radius of the ball $(\mathrm{m})$

$R_{c f} \quad$ Conductive thermal resistance through the lubricant film $(\mathrm{K} / \mathrm{W})$

$R_{e} \quad$ Effective contact radius of curvature along the direction of entraining motion $(\mathrm{m})$

$R_{f i} \quad$ Conductive thermal resistance of the moving heat source of surface $i(\mathrm{~K} / \mathrm{W})$

$r_{\mathrm{h}} \quad$ Radius of the circular Hertzian contact footprint (m)

$R_{s} \quad$ Effective contact radius of curvature along the side-leakage (lateral) direction $(\mathrm{m})$

$R_{z x} \quad$ Contact radius of curvature along the direction of entraining motion $(\mathrm{m})$

$t \quad$ Time (s)

$T \quad$ Temperature $(\mathrm{K})$

$T_{0, \text { ref }} \quad$ Reference temperature describing the viscositytemperature response of the lubricants $(\mathrm{K})$

$T_{\mathrm{a}} \quad$ Ambient temperature $(\mathrm{K})$

$T_{\text {bath }} \quad$ Lubricant bath temperature $\left(T_{\text {bath }}=T_{\mathrm{a}}\right)(\mathrm{K})$

$\bar{T}_{\mathrm{c}} \quad$ Average temperature rise at the centre of the EHD conjunction $(\mathrm{K})$

$T_{\mathrm{i}} \quad$ Inlet temperature of the lubricant $(\mathrm{K})$

$T_{\text {ref }} \quad$ Reference temperature of the lubricant for the TTS shifting $\left(70{ }^{\circ} \mathrm{C}\right)(\mathrm{K})$

$U \quad$ Lubricant's entraining velocity $(\mathrm{m} / \mathrm{s}, \mathrm{mm} / \mathrm{s})$

$U_{e} \quad$ Chittenden-Dowson dimensionless speed parameter (-)

$U_{i} \quad$ Surface velocity of solid $i$ in the direction of entraining motion $(\mathrm{m} / \mathrm{s})$

$V \quad$ Velocity of the lubricant in the lateral (sideleakage) direction $(\mathrm{m} / \mathrm{s})$

$W \quad$ Contact load $(\mathrm{N})$

$W_{e} \quad$ Chittenden-Dowson dimensionless load parameter $(-)$

$x \quad$ Distance along the direction of entraining motion (m)

$X \quad$ Dimensionless distance along the direction of entraining motion (-)

$z \quad$ Direction into the depth of lubricant film $(\mathrm{m})$

$Z \quad$ PV index of the lubricant (-)

\section{Greek symbols}

$\alpha^{*} \quad$ Reciprocal asymptotic iso-viscous PV coefficient $\left(\mathrm{GPa}^{-1}\right)$

$\alpha_{\mathrm{HN}} \quad$ Havriliak-Negami exponent (-)

$\alpha_{\mathrm{R}} \quad$ Roelands' PV coefficient $\left(\mathrm{GPa}^{-1}\right)$
$\beta_{\mathrm{HN}} \quad$ Havriliak-Negami exponent (-)

$\dot{\gamma} \quad$ Shear rate $\left(\mathrm{s}^{-1}\right)$

$\gamma_{\mathrm{L}} \quad$ Limiting shear stress-pressure proportionality coefficient (-)

$\Delta U \quad$ Sliding velocity $\left(\Delta U=U_{1}-U_{2}\right)(\mathrm{m} / \mathrm{s})$

$\left(\Delta T_{\mathrm{f}}\right)_{\mathrm{av}} \quad$ Average flash temperature rise $(\mathrm{K})$

$\left(\Delta T_{\text {oil }}\right)_{\text {av }}$ Average temperature rise due to the shear heating of the lubricant $(\mathrm{K})$

$\Delta T_{\mathrm{i}} \quad$ Inlet temperature rise $(\mathrm{K})$

$\eta \quad$ Apparent viscosity of the lubricant (Pa.s)

$\eta_{0} \quad$ Dynamic viscosity of the lubricant at low shear rate (Pa.s)

$\eta_{0 \text {,ref }} \quad$ Dynamic viscosity of the lubricant at low shear rate at the reference temperature ( $\mathrm{Pas})$

$\theta \quad$ Temperature $\left({ }^{\circ} \mathrm{C}\right)$

$\vartheta^{k} \quad$ Parameter value for the $k$ th iteration (-)

$\lambda \quad$ Relaxation time of the lubricant $(\mathrm{s})$

$\lambda_{s} \quad$ Lamda ratio $\left(\lambda_{s}=h_{\mathrm{c}} / \sigma_{\mathrm{qc}}\right)$

$\mu \quad$ Coefficient of friction (-)

$v_{\mathrm{b}} \quad$ Poisson's ratio of the ball (steel) (-)

$v_{\mathrm{d}} \quad$ Poisson's ratio of the disc (steel or glass) (-)

$\rho \quad$ Density of the lubricant $\left(\mathrm{kg} / \mathrm{m}^{3}\right)$

$\sigma_{\mathrm{qc}} \quad$ Combined root mean square surface roughness of the ball and the disc $(\mathrm{m})$

$\tau \quad$ Local shear stress $(\mathrm{Pa})$

$\bar{\tau} \quad$ Average shear stress in the EHD conjunction (Pa)

$\tau_{\mathrm{L}} \quad$ Limiting shear stress of the lubricant $(\mathrm{Pa})$

$\tau_{\mathrm{L}, 0} \quad$ Limiting shear stress of the lubricant at low pressure $(\mathrm{Pa})$

$\Phi_{\mathrm{T}} \quad$ Gupta's [39] thermal reduction coefficient (-)

$\chi_{s, i} \quad$ Thermal diffusivity of solid body $i$ ( $i=1$ for ball and $i=2$ for disc) $\left(\mathrm{m}^{2} / \mathrm{s}\right)$

\section{Introduction}

The elastohydrodynamic (EHD) regime of lubrication is the most frequently encountered in non-conforming lubricated conjunctions such as in meshing gears, rolling element bearings and cam-follower contacts [1, 2]. In the EHD regime of lubrication, piezo-viscous action of the lubricant is accompanied by the localised Hertzian deformation of contacting surfaces. A typical EHD contact comprises three distinct regions: (1) the inlet region, where the lubricant is entrained into the contact and rapid buildup of pressure occurs; (2) the central (high-pressure) contact region, where the lubricant film acts like a glassy solid with high viscosity and an almost uniform film thickness; and (3) the outlet region, where a sharp negative pressure gradient leads to lubricant film rupture and cavitation. Initial predictive analyses assumed lubricant viscosity in 
the inlet region to be the same as its dynamic atmospheric bulk value [3-6]. Invariably, this assumption can lead to an overestimation of lubricant film thickness. Consequently, an inaccurate estimation of load carrying capacity and contact friction can occur [7]. This inaccuracy arises as the result of three interacting phenomena in the inlet region: lubricant inlet shear heating [8,9], inlet lubricant shear thinning [10] and starvation [11, 12], which often occurs as the result of inlet swirl and back flows [13, 14].

The inlet shear heating is caused by viscous shear of the lubricant in the inlet zone, which leads to a subsequent decrease in the lubricant dynamic viscosity. Shear stress induces lubricant molecular alignment in the direction of shear (entraining motion). Starvation is due to an insufficient meniscus for the entrainment of lubricant into the conjunction. The combined effect of these phenomena can lead to reduced film thickness and thus a decreased load carrying capacity for a given film thickness, as well as increased friction. Hence, the conventionally assumed fully flooded inlet under isothermal conditions with Newtonian viscous shear should be regarded as idealistic.

Many machines and mechanisms operate at increasing contact pressures because of the recent trend in component downsizing. This is usually combined with high shear rates. These conditions have led to thinner lubricant films and higher generated contact temperatures, promoting thermal non-Newtonian EHD regime of lubrication. The pioneering studies focusing purely on the EHD traction commenced with the works of Crook $[15,16]$, highlighting the importance of temperature and pressure on lubricant viscosity. Plint [17] and Johnson and Cameron [18] pointed to the presence of a traction plateau in EHD contacts under high shear. Crook [16] explained this phenomenon in terms of generated heat and attributed it to a limiting shear stress. Hirst and Moore [19] pointed out that with high shear stress the lubricant behaviour in an EHD conjunction needs to be represented with non-Newtonian rheological functions. They recommended that once the shear stress exceeds a critical value, the shear rate would no longer be proportional to the shear stress. Johnson and Tevaarwerk [20] introduced a nonlinear Maxwell (elasto-plastic) model to describe the rheological behaviour of common lubricants under such conditions. For the viscous response of the lubricant, they recommended the use of an Eyring-like law, based on a hyperbolic sine function [21]. Johnson and Tevaarwerk [20] model has been extensively used, particularly for highly loaded contacts at high shear rates, for example in the case of hypoid gear pairs [22, 23]. Bair and Winer [24] assumed that the lubricant would behave as a Maxwell fluid and introduced a non-Newtonian rheological model in which the extent of shear thinning was controlled by the magnitude of shear stress combined with the limiting shear stress.
The Eyring-like models make use of a limiting shear stress, commonly referred to as the Eyring shear stress, $\tau_{0}$ with the implication that shear below this value may be regarded as Newtonian [20]. When the shear stress exceeds this limiting value, then the shear thinning effect can no longer be neglected. In the early stages of the development of the EHD theory, the Eyring shear stress value was determined through measurements of the coefficient of friction, often using a disc machine [20]. However, with disc machines, generated temperatures and pressures at each point in the contact cannot be controlled and are generally unknown. This leads to measurements which correspond to conditions which are averaged throughout the contact footprint, which can induce inaccuracies when employed to validate EHD models under a wide variety of operating conditions and applications. A way to overcome this limitation is through use of high-shear viscometry, which allows for a better control of generated temperatures and the pressures. Bair $[25,26]$ has highlighted the use of high-pressure viscometry, also for shear thinning lubricants. His work points to the use of Carreau-Yasuda model [27] as the most appropriate rheological lubricant response model, subjected to high shear. Based on this model, combined with measurements of high-shear/high-pressure response of several different lubricants, successful predictions of the EHD coefficient of friction and film thickness have been reported, both analytically [28] and numerically [29].

The current study presents a methodology for prediction of coefficient of friction and the lubricant film thickness for highly loaded EHD contacts with medium-to-high lubricant shear, similar to the conditions experienced in automotive differential hypoid gears. The study extends the reported work in the literature to include the rheological effect of fully formulated gear lubricants. It also incorporates the effect of inlet shear heating (ISH) and starvation on the performance of EHD contacts, which is of particular importance, especially at higher entraining velocities. This approach integrates the inlet conditions with the frictional performance of EHD contacts, an approach not hitherto reported in the literature. The reported analysis is verified by experimental investigations, using interferometry as well as friction measurement using a mini traction machine (MTM).

\section{Theoretical Model}

An analytical non-Newtonian thermo-elastohydrodynamic (TEHD) model is presented. The model is used to predict film thickness and friction for circular point contact of a rigid ball against a flat semi-infinite elastic half-space of equivalent elastic modulus $E^{\prime}$. An MTM is employed for 
the purpose of validation of the predictive friction model. In addition, an optical interferometer is used to provide further verification for the predicted lubricant film thickness in the central flat region of the contact.

The friction model accounts for the non-Newtonian shear thinning behaviour of the lubricant film. Furthermore, the model is combined with an analytical thermal model in order to predict the rise in the lubricant temperature due to ISH. The effect of contact starvation is also included.

\subsection{The Friction Model}

The following assumptions are made:

1. The generated EHD pressure profile closely follows the Hertzian pressure profile, except for the inlet trail and the secondary pressure peak in the vicinity of contact outlet [1]. This assumption alleviates the need for the full solution of Reynolds equation, implying application of medium-to-high loads (piezo-viscous elastic: EHD).

2. The central region of the film shape is regarded as flat at the height of the central oil film thickness. The film thickness is predicted, using the extrapolated oil film thickness formula reported by Chittenden et al. [30] and is based on an assumed fully flooded inlet. The effects of ISH and starvation on the predicted central film thickness are taken into account through corrective procedures, applied to the inlet lubricant viscosity, as well as the determination of the inlet distance through implementation of the starvation effect.

3. The inlet shear thinning is not taken into account. This is considered to be a fair assumption for the lubricants examined due to the additives' relatively lower molecular weight compared with the common engine oils.

4. Steady-state conditions are assumed. Therefore, no squeeze film effect is taken into account (load and the entraining velocity remain constant throughout the MTM experiments).

5. The contiguous contacting surfaces are assumed to be perfectly smooth.

Based on the above-stated assumptions, the EHD problem is formulated by employing a relatively simple set of equations, eliminating the need for a computationally intensive numerical solution.

The central film thickness is obtained as [4]:

$h_{\mathrm{c}}=4.31 R_{e} U_{e}^{0.68} G^{0.49} W_{e}^{-0.073}\left[1-\exp \left(-1.23\left(\frac{R_{s}}{R_{e}}\right)^{2 / 3}\right)\right]$ in which the dimensionless speed, material and load parameters are:

$$
\begin{aligned}
& U_{e}=\frac{\eta_{0}\left(T_{\mathrm{in}}\right) U}{E^{\prime} R_{e}}, \quad G=\alpha^{*}\left(T_{\mathrm{in}}\right) E^{\prime}, \quad W_{e}=\frac{W}{E^{\prime} R_{e}^{2}} \quad \text { where } \\
& \frac{2}{E^{\prime}}=\frac{1-v_{\mathrm{b}}^{2}}{E_{\mathrm{b}}}+\frac{1-v_{\mathrm{d}}^{2}}{E_{\mathrm{d}}}
\end{aligned}
$$

The atmospheric dynamic viscosity, $\eta_{0}$, and the pressure-viscosity coefficient, $\alpha^{*}$, are calculated at the inlet temperature of $T_{\mathrm{i}}$. The inlet temperature usually exceeds that of the oil bath, $T_{\mathrm{b}}$ due to inlet shear heating.

The principal radii of curvature in the direction of entraining motion and that in the side-leakage direction: $R_{e}$ and $R_{s}$, are considered to be the same for the circular point contact configuration (radius of the ball, $R_{\mathrm{b}}=9.525 \mathrm{~mm}$ ). In the cases examined, there is negligible side-leakage flow since the rotation of the ball against the flat disc occurs in only one principal plane of contact, and thus, $V=0$. The coefficient of friction for the EHD conjunction is calculated, based on the assumption that its magnitude is mainly dominated by the conditions at the central region of the contact [31], which is strongly dependent on the inlet conjunctional conditions. The lubricant within the flat central region of the EHD contact is mainly subject to Couette flow. The effect of pressure gradient on shear is low compared with that due to the relative motion of contiguous surfaces.

Hence, the flow of lubricant due to pressure gradient can be neglected as is commonly assumed in analytical EHD solution, where:

$\dot{\gamma}=\frac{\Delta U}{h_{\mathrm{c}}}$

Shear stress is obtained as:

$\tau=\eta(p, \dot{\gamma}) \dot{\gamma}$

where $\eta$ is the effective dynamic viscosity. The limiting shear stress is a function of pressure [32] as:

$\tau_{\mathrm{L}}=\tau_{\mathrm{L}, 0}+\gamma_{\mathrm{L}} p$

For polyalphaolefin (PAO) base oils, Hoglund and Jacobson [32] recommended $\gamma_{L}=0.029$ at $40^{\circ} \mathrm{C}$. However, no data are available for the slope, $\gamma_{\mathrm{L}}$, at temperatures other than $40^{\circ} \mathrm{C}$. Hence, a temperature-invariant slope is assumed in the current study. The constant $\tau_{\mathrm{L}, 0}=4.0 \mathrm{MPa}$ is in the range recommended by Stahl and Jacobson [33] (1-8 MPa). Therefore, the limiting shear stress is evaluated locally within the contact footprint in accord with the generated pressures. For a Hertzian pressure distribution within a circular contact footprint:

$p=p_{\mathrm{h}} \sqrt{\left(1-r^{2}\right)}$ 
where the maximum Hertzian pressure, $p_{\mathrm{h}}$, is:

$p_{\mathrm{h}}=\frac{3 W}{2 \pi r_{\mathrm{h}}^{2}}$

and the contact radius is:

$r_{\mathrm{h}}=\left(\frac{3 W R_{\text {ball }}}{E^{\prime}}\right)^{1 / 3}$

The coefficient of friction is, therefore, obtained as:

$\mu=\frac{\bar{\tau}}{\bar{p}}$

where $\bar{p}$ is the average Hertzian contact pressure and $\bar{\tau}$ is the average shear stress in the EHD contact:

$\bar{\tau}=\int_{0}^{1} 2 r \tau \mathrm{d} r$

\subsection{Thermal Model}

The rise in lubricant temperature at the inlet and in transition through the contact conjunction is calculated, using a thermal network model shown in Fig. 1. The thermal model presented is similar to those reported by Olver [34] for gear contacts and Morris et al. [35] for the compression ring conjunction in an engine. This is extended to take into account the influence of inlet shear heating of the lubricant. The following assumptions are made:

1. The inlet temperatures of the contacting surfaces (e.g. the ball and the disc in the MTM) are assumed to be the same as that of the bulk oil, implying perfect cooling of the surfaces. This is a simplifying assumption made for the purpose of the current study. It is evident that any rise in surface temperature can readily be incorporated, providing a suitable convection model from surfaces to the bulk oil would be included. However, this effect is rather trivial with regard to the main objectives of the study.

2. The generated heat in the inlet zone is not conducted to the adjacent solids.
3. The temperature distribution in the central region of the conjunction is uniform and an average temperature rise within the contact is calculated above that at the inlet zone. This is due to the shear of the lubricant film.

4. The thermal properties of the lubricant and the adjacent solid surfaces (such as thermal conductivity) remain constant with any rise in temperature and pressure.

5. In the central region of the contact, the generated heat is dissipated through conduction to the solid surfaces. This assumption is justified as convective heat transfer of thin elastohydrodynamic films is rather negligible [36].

The thermal model is based on the principle of heat partitioning between the surfaces in the contact conjunction (Fig. 1). The rate of generated heat in the central region of the contact is:

$\dot{q}=\mu W|\Delta U|$

where the viscous shear heating of lubricant is transferred in proportions: $a_{\mathrm{h}}$ and $\left(1-a_{\mathrm{h}}\right)$ to the adjacent contacting surfaces, and where: $0 \leq a_{\mathrm{h}} \leq 1$. Assuming that the heat is produced in the mid-plane of the contact, the main thermal resistances are: (1) the conductive heat resistance through half the thickness of the lubricant film, $R_{c f}$, which is the same for both the contacting surfaces and (2) the transient heat conduction to the solid bodies, $R_{f i}(i=1,2$ for the ball and the disc, respectively). These heat resistant sources are estimated as [34]:

$R_{c f}=\frac{h_{\mathrm{c}}}{2 k_{f} A_{\mathrm{EHL}}} \quad$ and $\quad R_{f i}=\frac{1.06}{A_{\mathrm{EHL}} k_{s}} \sqrt{\frac{2 \chi_{s, i} r_{\mathrm{h}}}{U_{i}}}$

The heat partition coefficient is [36]:

$a_{\mathrm{h}}=\frac{R_{f 2}+R_{c f}}{R_{f 1}+R_{f 2}+2 R_{c f}}$

The average temperature at the centre of the conjunction can now be calculated as:

$\bar{T}_{\mathrm{c}}=T_{\mathrm{i}}+\left(\Delta T_{f}\right)_{\mathrm{av}}+\left(\Delta T_{\mathrm{oil}}\right)_{\mathrm{av}}$

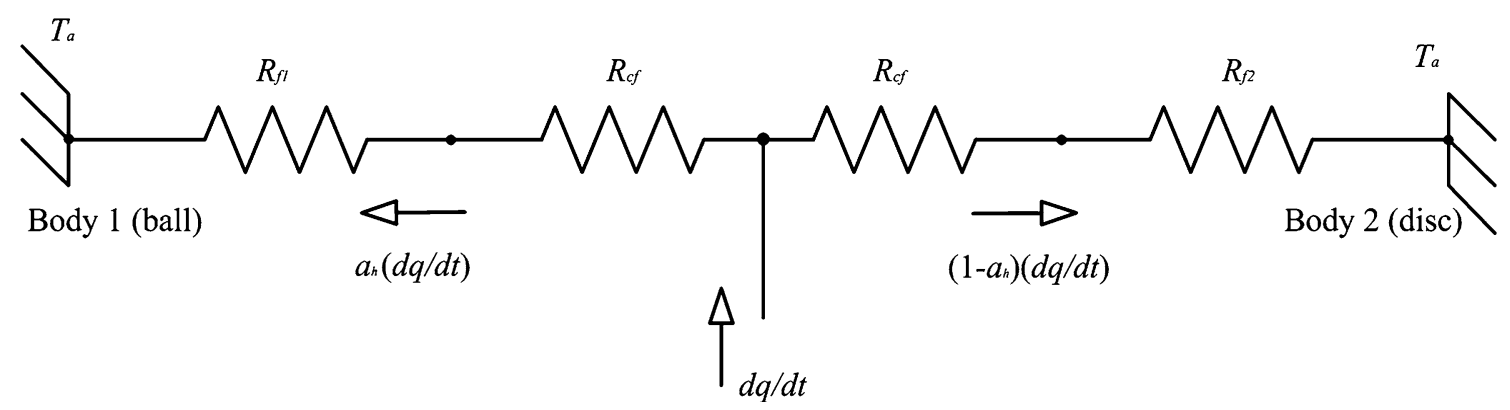

Fig. 1 Thermal network considered 
The average flash temperature rise, $\left(\Delta T_{\mathrm{f}}\right)_{\mathrm{av}}$, and the temperature rise due to the lubricant shear, $\left(\Delta T_{\mathrm{oil}}\right)_{\mathrm{av}}$, are obtained as:

$$
\left(\Delta T_{f}\right)_{\mathrm{av}}=R_{f 1} a_{\mathrm{h}} \dot{q} \quad \text { and } \quad\left(\Delta T_{\mathrm{oil}}\right)_{\mathrm{av}}=\frac{|\Delta U| \bar{\tau} h_{\mathrm{c}}}{8 k_{f}}
$$

In Eq. (14), $T_{\mathrm{i}}$ is the inlet temperature of the lubricant. Its value is influenced by the bulk lubricant temperature (bath temperature). The inlet temperature rises due to shear heating. The procedure to evaluate the inlet lubricant temperature rise is described below.

\subsection{Inlet Zone Thermal Analysis}

In order to estimate the rise in the inlet lubricant temperature, the following assumptions are made:

1. Shearing of the lubricant in the inlet zone follows Newtonian behaviour; thus, the effect of inlet shear thinning is neglected.

2. The thickness of the lubricant film at the inlet point $x=-r_{\mathrm{h}}$ is the same as that of the central contact film thickness, $h_{\mathrm{c}}$.

3. The pressure gradient is the main driving force in the inlet flow wedge along the direction of entraining motion [2].

4. The thermal properties of the lubricant do not vary significantly with temperature.

The energy equation for the inlet zone of the EHD conjunction is expressed, based on the approach followed by Greenwood and Kauzlarich [9] as:

$-\left.k_{f} \frac{\mathrm{d}^{2} T}{\mathrm{~d} z^{2}}\right|_{x=-r_{\mathrm{h}}}=\frac{z^{2}}{\eta_{0}\left(p_{\mathrm{a}}, T_{\mathrm{i}}\right)}\left(\left.\frac{\mathrm{d} p}{\mathrm{~d} x}\right|_{x=-r_{\mathrm{h}}}\right)^{2}$

The pressure gradient at the inlet, located at $x=-r_{\mathrm{h}}$, along the direction of entraining motion cannot be determined analytically. In order to overcome this difficulty, an alternative approach is followed, where the entrance to the EHD contact according to Grubin [37] is where the inlet trail merges into the Hertzian pressure profile: $p_{\mathrm{i}} \approx 1 / a^{*}$ at $X=x / r_{\mathrm{h}}=-1$ [38]. Since the pressure at the centre of the conjunction is $p=p_{\mathrm{h}}$, the pressure gradient along the direction of entraining motion at the inlet of the contact can be approximated by:

$\left.\frac{\mathrm{d} p}{\mathrm{~d} x}\right|_{x=-r_{\mathrm{h}}} \approx \frac{p_{\mathrm{h}}-\left(1 / \alpha^{*}\right)}{r_{\mathrm{h}}}$

Figure 2 illustrates the concept of inlet pressure gradient approximation, and the main disadvantages are:

1. The real inlet pressure rise rate would generally be higher than this approximation by $10-15 \%$, since the

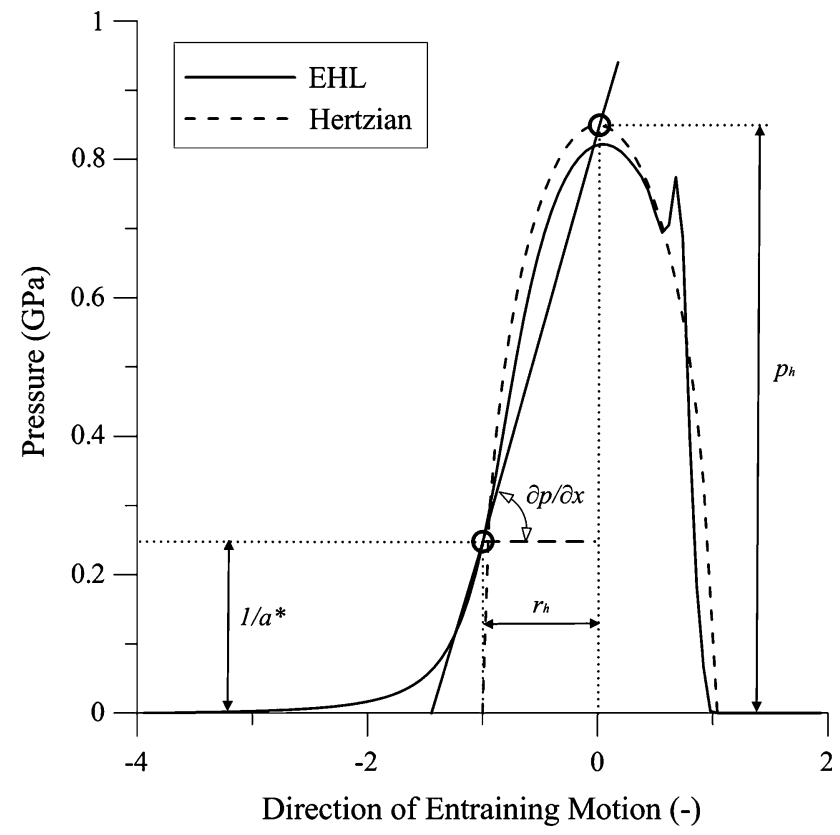

Fig. 2 Schematic of the approximation of the pressure gradient at the inlet of the EHD conjunction

discrete points of known pressure used have a significant distance between them (equal to the radius of the circular contact footprint).

2. The variation of slide-roll ratio (SRR) is not taken into account in the calculation of the inlet temperature rise as Eq. (16) assumes pure rolling conditions at the inlet conjunction. It is known that increasing SRR leads to increased inlet temperature rise [39]. However, given the conditions and the properties of the lubricants used in this study, the difference between the thermal reduction coefficient (Eq. 20) under pure rolling and that with $50 \%$ SRR is merely $8 \%$ [39]. Therefore, it is reasonable to apply the ISH described here to higher SRR values, representing the conditions encountered in MTM testing without incurring any significant error.

Integrating Eq. (16) across the film and setting: $T(z=0)=T\left(z=h_{\mathrm{c}}\right)=T_{\mathrm{b}}$, the temperature rise in the inlet zone for $z=h_{\mathrm{c}} / 2$ can be estimated as (see "Appendix $1 ")$ :

$\Delta T_{\mathrm{i}}=T_{\mathrm{i}}-T_{\text {bath }}=\frac{5}{64} \frac{h_{\mathrm{c}}^{4}}{k_{f} \eta_{0}\left(p_{\mathrm{a}}, T_{\mathrm{i}}\right) r_{\mathrm{h}}^{2}}\left(p_{\mathrm{h}}-\frac{1}{\alpha^{*}}\right)^{2}$

Since the lubricant properties and the central oil film thickness are functions of the inlet temperature, an iterative method is used to evaluate an exact value for the inlet temperature due to ISH. Replacing for the central oil film thickness from Chittenden-Dowson [4], Eq. (18) can be rewritten as: 
$\Delta T_{\mathrm{i}}=0.9567 \frac{\eta_{0}\left(p_{\mathrm{a}}, T_{\mathrm{i}}\right)^{1.72} U^{2.72} \alpha^{* 1.96}}{k_{f} E^{\prime 0.532} R_{z x}^{3.136} W^{0.292}}\left(1-\frac{p_{\mathrm{i}}}{p_{\mathrm{h}}}\right)^{2}$

where $p_{\mathrm{i}}=1 / \alpha^{*}$. An observation of the parameters appearing in Eq. (19) shows that inlet temperature rise is proportional to the sliding velocity as: $\Delta T_{\mathrm{i}} \propto U^{2.72}$. Furthermore, the proportionality between the inlet temperature rise and the central oil film thickness $\left(\Delta T_{\mathrm{i}} \propto h_{\mathrm{c}}^{4}\right)$ suggests that ISH would be suppressed with any degree of starvation, which would be an expected outcome. This statement is further supported by the results presented later.

The thermal properties of the steel MTM specimen and the lubricants examined are listed in Table 1.

The film thickness and the inlet temperature are directly affected by the lubricant viscosity at the inlet to the conjunction [31]. A comparative study of the experimentally measured central film thickness and the predictions using Chittenden-Dowson [4] formula can be made, augmented by the effect of ISH (Sect. 6.1). In the case of ISH, a "thermal reduction coefficient" can be used to adjust the predicted lubricant film thickness [39]:

$\Phi_{\mathrm{T}}=\frac{1-13.2\left(\frac{p_{\mathrm{h}}}{E^{\prime}}\right) L^{0.42}}{1+0.213\left(1+2.23 \operatorname{SRR}^{0.83}\right) L^{0.64}}$

where the thermal reduction coefficient, $L$, is given as:

$L=-\left.\frac{\partial \eta}{\partial T}\right|_{T_{\mathrm{b}}} \frac{U^{2}}{k_{f}}$

Once the thermal reduction coefficient is determined, the reduced central film thickness can be estimated by:

$h_{\mathrm{c}, \mathrm{ISH}}=\Phi_{\mathrm{T}} h_{\mathrm{c}, \text { iso }}$

\subsection{Contact Starvation}

Lubricant starvation occurs as the result of an insufficient volume of inlet meniscus from which the lubricant is entrained into the contact. This reduces the EHD oil film thickness, particularly at higher entraining velocities. There is a plethora of experimental and theoretical studies $[12,40]$. However, there still seems to be a dearth of analysis with respect to the effect of starvation on EHD friction, except for the recent work in Mohammadpour et al. [14] for light-to-medium loads. Furthermore, the interaction between the mechanisms of ISH and lubricant starvation at the inlet has not hitherto been sufficiently investigated.

Table 1 Thermal properties of the materials involved
To address the effect of starvation, the method highlighted by Zaretsky [41] is used in this study. Therefore, a film reduction factor due to starvation, $\Phi_{\mathrm{S}}$, is introduced in the present study according to the experimental data available in [41]:

$\Phi_{\mathrm{S}}=\left\{\begin{array}{cl}1, & \text { if } G \cdot U_{e}<2 \cdot 10^{-7} \\ 0.0028 L_{\mathrm{cor}}\left(G \cdot U_{e}\right)^{-0.369,}, & \text { if } G \cdot U_{e} \geq 2 \cdot 10^{-7}\end{array}\right.$

where $L_{\text {cor }}$ represents a correction coefficient introduced to achieve a good agreement with the experimentally determined starvation film reduction factor presented in [41]. Its value can be calculated using a polynomial function as (see “Appendix 2"):

$$
\begin{aligned}
L_{\mathrm{cor}}= & a_{1}\left(G \cdot U_{e}\right)^{4}+a_{2}\left(G \cdot U_{e}\right)^{3}+a_{3}\left(G \cdot U_{e}\right)^{2}+a_{4}\left(G \cdot U_{e}\right) \\
& +a_{5}
\end{aligned}
$$

The coefficients $a_{i}, i=1 \sim 5$ are also provided in "Appendix 2". The corresponding starvation film reduction factor, determined from Eq. (23), is plotted against the lubricant flow number $\left(G \cdot U_{e}\right)$ in Fig. 3. For lubricant flow numbers below $2 \times 10^{-7}$, the starvation film reduction factor, $\Phi_{\mathrm{S}}$, is always unity [41].

The film reduction factor due to starvation, $\Phi_{\mathrm{S}}$, is used to correct the predictions obtained using the ChittendenDowson equation [30]. Whenever necessary, the ISH is accounted for by adjusting the inlet viscosity, since the inlet temperature is known a priori. The corrected central film thickness can then be found.

\section{Characterisation of the Axle Lubricant}

The lubricants examined have been characterised in terms of their viscosity under high-pressure, high-temperature and high-shear-rate conditions. By combining the knowledge of these parameters, it is possible to predict their EHD tractive behaviour. The three lubricants under examination are fully formulated oils. The base oil is polyalphaolefin (PAO), blended with different additive packages. The difference between these additive packs is on the type of viscosity modifier (VM) used. The grade of the lubricants is SAE 75W-90. The differences in the additive packs lead to differences in their high-shear response, since each VM has a different molecular weight.

\begin{tabular}{llll}
\hline Property (unit) & Symbol & Solid bodies & Lubricants (1-3) \\
\hline Thermal conductivity $(\mathrm{W} / \mathrm{mK})$ & $k_{s}, k_{f}$ & 30.0 (steel), 1.4 (glass) & 0.18 \\
Heat capacity $\left(\mathrm{J} / \mathrm{kg}^{\circ} \mathrm{C}\right)$ & $c_{p, s}, c_{p, f}$ & 490.0 (steel), 840.0 (glass) & 2090.0 \\
\hline
\end{tabular}




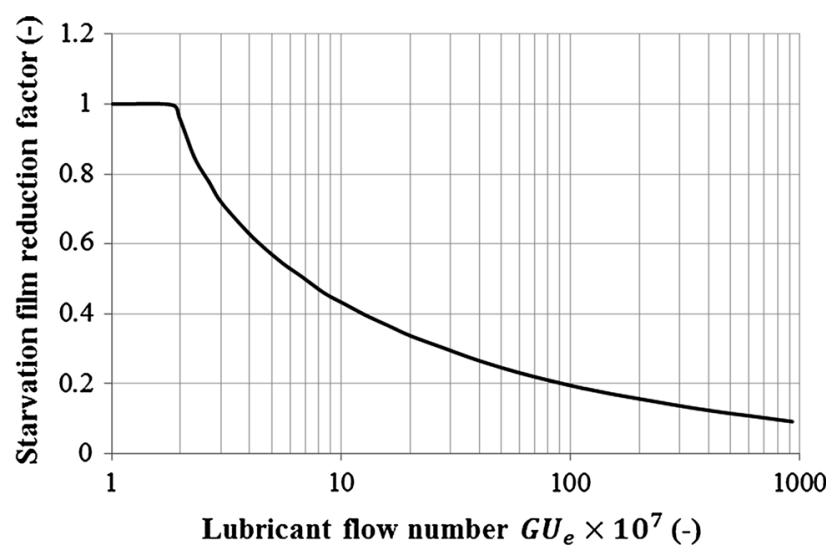

Fig. 3 Variation of the film reduction factor due to starvation with the lubricant flow number

\subsection{High-Pressure-Low-Shear Viscosity Characteristics}

A high-pressure viscometer is employed to determine the low-shear dynamic viscosity of the lubricants under examination at three different temperatures: 40, 100 and $140^{\circ} \mathrm{C}$. For higher pressures, one can obtain the PV coefficient using the relationship provided by Bair et al. [42]:

$\alpha^{*}=\left[\int_{0}^{\infty} \frac{\eta(p=0) \mathrm{d} p}{\eta(p)}\right]^{-1}$

In the present analysis, it is assumed that the reciprocal asymptotic iso-viscous $\mathrm{PV}$ coefficient is responsible for the EHD film formation in the conjunction according to [43].

The pressure dependence of the lubricant's low-shear dynamic viscosity is described by Roelands' equation [44] as expressed by Houpert [45]:

$\eta_{0}(p, T)=\eta_{0}\left(p_{\mathrm{a}}, T\right) \exp \left(\alpha_{\mathrm{R}} p\right)$

The value of $\alpha_{R}$ depends on pressure and it can be evaluated by [45]:

$\alpha_{\mathrm{R}}=\frac{\left\{\ln \left[\eta_{0}\left(p_{\mathrm{a}}, T\right)\right]+9.67\right\}\left[\left(1+5.1 \times 10^{-9} p\right)^{Z}-1\right]}{p}$

The PV index is given as [45]:

$Z=\frac{\alpha^{*}(T)}{5.1 \times 10^{-9}\left\{\ln \left[\eta_{0}\left(p_{\mathrm{a}}, T\right)\right]+9.67\right\}}$

\subsection{Characterisation of High-Temperature-Low- Pressure Shear Dynamic Viscosity}

The examined lubricants have also been characterised in terms of their low-shear dynamic viscosity at atmospheric pressure and elevating temperatures. The temperature
Table 2 Low-shear dynamic viscosity temperature dependence parameters

\begin{tabular}{llll}
\hline Lubricant & $\eta_{0, \text { ref }}(\mathrm{Pas})$ & $A_{1}(\mathrm{~K})$ & $T_{0, \text { ref }}(\mathrm{K})$ \\
\hline 1 & $1.55 \times 10^{-4}$ & 944.8 & 165.2 \\
2 & $1.57 \times 10^{-4}$ & 951.0 & 164.0 \\
3 & $8.70 \times 10^{-5}$ & 1074.1 & 161.0 \\
\hline
\end{tabular}

range examined is: $10-140{ }^{\circ} \mathrm{C}$. The following expression is used to describe the temperature dependence of these gear lubricants as is recommended by the suppliers:

$\eta_{0}\left(p_{\mathrm{a}}, T\right)=\eta_{0, \text { ref }}\left(p_{\mathrm{a}}\right) \exp \left(\frac{A_{1}}{T-T_{0, \text { ref }}}\right)$

The temperature $T$ is expressed in $\mathrm{K}$. Table 2 lists the constants appearing in Eq. (29) for each of the lubricants used.

\subsection{Characterisation of High-Shear Viscosity}

The high-shear-rate response of lubricant viscosity is characterised using an ultra-high-shear viscometer (USV) for four different temperatures: $70,80,100$ and $140{ }^{\circ} \mathrm{C}$. The determination of high-shear-rate response at different temperatures allows the introduction of a shifting law [46]. The model can be used to extend the description of rheological shear behaviour of lubricants to temperatures beyond the reference temperature. This is accomplished by employing the time-temperature superposition (TTS) theory [46]. The chosen reference temperature for the highshear-rate viscosity measurements of the lubricants used is $T_{\text {ref }}=70^{\circ} \mathrm{C}$ in the current study. The rheological model chosen to fit the high-shear-rate viscosity measurements is that of Havriliak-Negami [47], which for lubricants with purely visco-plastic behaviour is described as:

$\eta(\dot{\gamma}, T)=\frac{\eta_{0}(T)}{\left[1+\left(a_{\mathrm{TTS}}(T) \lambda \dot{\gamma}\right)^{\alpha_{\mathrm{HN}}}\right]^{\beta_{\mathrm{HN}}}}$

where $\eta_{0}(T)$ is the low-shear dynamic viscosity of a lubricant at temperature $T$ (expressed in $\mathrm{K}$ ) and $\lambda$ is its relaxation time with the additives in the solution, determined at the reference temperature of $T_{\text {ref. }}$. In addition, $\alpha_{\mathrm{HN}}$ and $\beta_{\mathrm{HN}}$ are exponents which depend on the molecular weight of the polymers in the blend (again determined at $T_{\text {ref }}$ ), and $a_{\mathrm{TTS}}(T)$ is the TTS shifting factor which is used to describe the high-shear-rate viscosity of the lubricant at temperatures $T \neq T_{\text {ref. }}$. It is found that the TTS shifting factor, best describing the high-shear viscosity data for the present study, is:

$a_{\mathrm{TTS}}(T)=\frac{\eta_{0}(T)}{\eta_{0}\left(T_{\text {ref }}\right)} \frac{T_{\text {ref }}}{T} \frac{\rho\left(T_{\text {ref }}\right)}{\rho(T)}$ 
Table 3 Non-Newtonian rheological parameters of the examined lubricants

\begin{tabular}{llll}
\hline Lubricant & $\alpha_{\mathrm{HN}}$ & $\beta_{\mathrm{HN}}$ & $\lambda(\mathrm{s})$ \\
\hline 1 & 0.703 & 1.0 & $7.9 \times 10^{-8}$ \\
2 & 0.606 & 1.0 & $9.1 \times 10^{-8}$ \\
3 & 0.729 & 1.0 & $4.9 \times 10^{-8}$ \\
\hline
\end{tabular}

The dependence of lubricant density on temperature is given by (using the available experimental data):

$\rho(T)=-0.6323 T+1016.1$

For the lubricants used, the coefficients appearing in Eq. (30) are listed in Table 3.

Special care should be taken with high-shear viscometry at ambient pressure due to the potential effect of shear cavitation. The USV employed to characterise the high-shear response of the lubricants operates at atmospheric pressure. As noted by Bair and Qureshi [48], high-shear measurements at atmospheric pressure are susceptible to the effect of shear cavitation, which can occur within the viscometer when the viscous shear stress experienced by a lubricant exceeds a critical value. This critical value is equal to or lower than the ambient pressure. Hence, for the case of the USV, the ambient pressure is equal to the atmospheric pressure, implying that when the viscous shear stress reaches the atmospheric pressure, the viscosity readings can be influenced by shear cavitation. For the present study, it is expected that shear cavitation influences the measurements of the USV for shear rates higher than $10^{6} \mathrm{~s}^{-1}$, after which point the corresponding shear stress becomes comparable to the ambient pressure. Due to the limitations of USV, in conjunction with the lack of data for high shear rates at high pressures, the fitting coefficients in Table 3 have been estimated at ambient pressure. Nonetheless, these coefficients can effectively describe the high-shear rheology of the lubricants up to the shear rate of $10^{6} \mathrm{~s}^{-1}$.

\section{Traction and Film Thickness Measurements}

An MTM is used to study the lubricant characteristics under the operating conditions (in terms of contact pressure and speed) similar to those experienced in gear pair contacts. Figure 4 is a schematic representation of the MTM. A loaded ball, attached to a rotating connecting rod, is loaded against a rotating disc, which is immersed into an oil bath during the experiment. The rotating velocities of the ball and the disc can be controlled independently so that a wide range of SRRs can be achieved. The frictional resistance applied to the loaded ball can be monitored through a transducer. Since the normal load between the

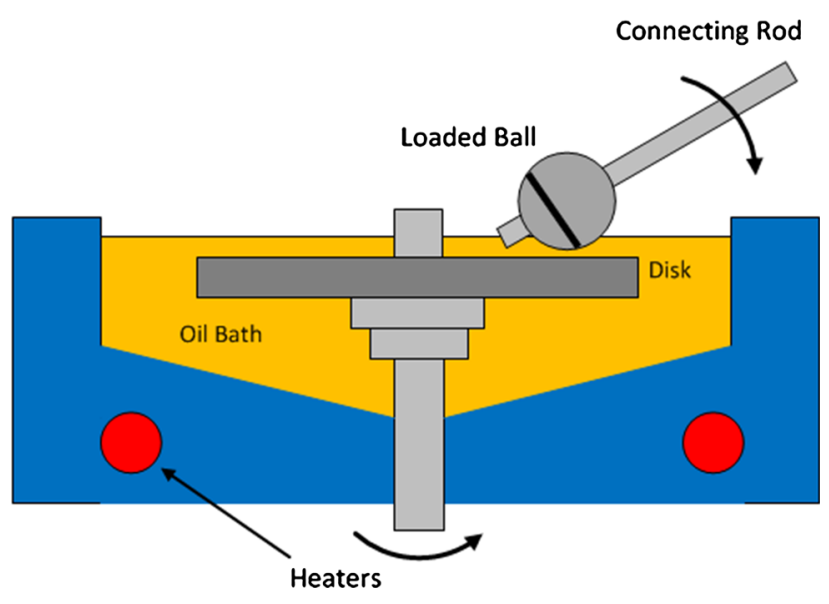

Fig. 4 Layout of the MTM

ball and the disc is known, the coefficient of friction can be ascertained. A network of heaters is embedded beneath the oil bath, permitting the control of the oil bath temperature. Both the ball and the disc specimen are made of steel.

Experimental traction curves were obtained for the three studied lubricants. The lubricant entraining velocity was kept constant at $2.5 \mathrm{~m} / \mathrm{s}$, whilst the contact load was kept at 20 N. SRR was varied from $0 \%$ (pure rolling) up to $50 \%$ (moderate sliding) during the experiments. The maximum contact pressure was maintained at $1 \mathrm{GPa}$, whilst three bath oil temperatures of 40,60 and $80^{\circ} \mathrm{C}$ were used. These conditions are common in hypoid gear pair conjunctions found in automotive differentials [51], where the contact pressure is within the range $1-1.5 \mathrm{GPa}$, the entraining velocity in the range $1-5 \mathrm{~m} / \mathrm{s}$, depending on the angular velocity of the pinion/ring gear with the sump temperature varying between 40 and $100{ }^{\circ} \mathrm{C}$, depending on speed and load. Before running the experiments, all specimens were thoroughly cleaned in a toluene ultrasonic bath, followed by an ultrasonic bath of acetone. Values of the EHD traction coefficient for varying SRR were recorded.

The experimental determination of the central film thickness was performed using an ultra-thin film optical EHD interferometer [49], the layout of which is shown in Fig. 5.

A steel ball of radius, $R_{\mathrm{b}}=9.525 \mathrm{~mm}$, supported by a pair of roller bearings, enables free rotation and is loaded against a flat rotating glass disc. The load between the steel ball and the glass disc is precisely controlled. The ball rolls against the glass disc with insignificant micro-sliding. Therefore, contact of the bodies results in a circular contact footprint. Due to the different refractive index of the air, the glass disc and the lubricant, combined with the fact that a portion of the light travelling through the glass is reflected at the intermediate interface between the disc and the lubricant, the interference fringe patterns yield a good estimation of the lubricant film thickness. 
Fig. 5 Layout of the optical interferometry rig

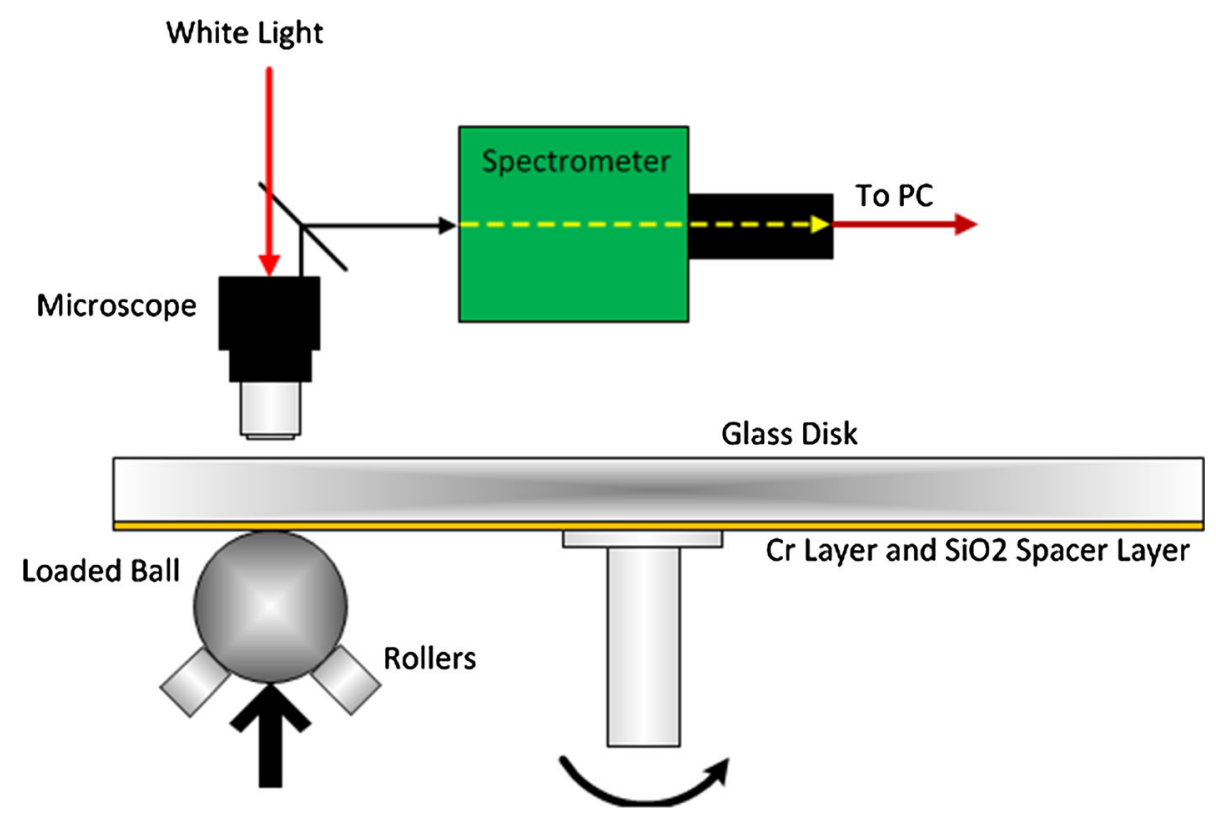

\subsection{Measurements of Surface Topography}

Topographical measurements were undertaken for all contacting surfaces in order to ascertain the chance of asperity contact between the counter faces and their subsequent effect upon the generated friction. The details of the procedure are provided in "Appendix 2". The findings of the surface roughness analysis indicate that the combined RMS surface roughness between the steel ball and the steel flat surfaces in the MTM tests was $\sigma_{\mathrm{qc}}=3.25 \mathrm{~nm}$. The corresponding lambda ratio is then found to be within $\lambda_{s}=h_{\mathrm{c}} / \sigma_{\mathrm{qc}}=10 \sim 100$, indicating negligible contribution due to asperity friction.

\section{Numerical Solution Procedure}

The following procedure is followed:

1. For each studied lubricant, its rheological properties are used. The operating conditions, such as the contact load, the SRR and the speed of lubricant entraining motion, are used.

2. The maximum and average Hertzian pressures are determined, together with the radius of the circular contact footprint. To estimate the properties of the lubricant at the contact centre and at the inlet conjunction, the corresponding temperatures are set to that of the bulk.

3. The Chittenden-Dowson [30] equation is employed to predict the central contact oil film thickness. The effect of ISH and starvation is also accounted for by utilising the film reduction factor due to starvation and the inlet lubricant viscosity. Since the central film thickness, the temperatures at the inlet and in the contact centre, as well as the Hertzian pressure, are known, the local shear stress can be calculated using Eq. (4).

4. Applying Eqs. (9) and (10) yields the coefficient of friction.

5. Subsequently, the heat production rate, $\dot{q}$, can be estimated.

6. Pressure at the inlet conjunction is set to $1 / \alpha^{*}$ in order to calculate the inlet temperature rise using Eq. (19).

7. The updated inlet and the average temperature rise at the centre of the contact are then used to recalculate the coefficient of friction using the previous steps. This iterative procedure is continued until the following convergence criterion is satisfied:

$$
\frac{\left|\vartheta^{k}-\vartheta^{k-1}\right|}{\left|\vartheta^{k}\right|}<0.01
$$

where $\vartheta \in\left\{T_{\mathrm{i}}, \bar{T}_{\mathrm{c}}\right\}$ corresponds to the parameter for which the convergence criterion is examined. The index $k$ indicates the iterative step within the procedure.

\section{Results and Discussion}

The predicted coefficient of friction and the central oil film thickness are compared with the measurements, using the MTM and the optical spectrometer under identical conditions. Variations of the inlet and average temperature rise at the centre of the conjunction with the prevailing SRR, the magnitude of the entraining velocity and the bath oil temperature are also recorded for three gear oils. 
Fig. 6 Central film thickness for a lubricant $1, \mathbf{b}$ lubricant 2 and c lubricant 3 at $40{ }^{\circ} \mathrm{C}$ bath oil temperature

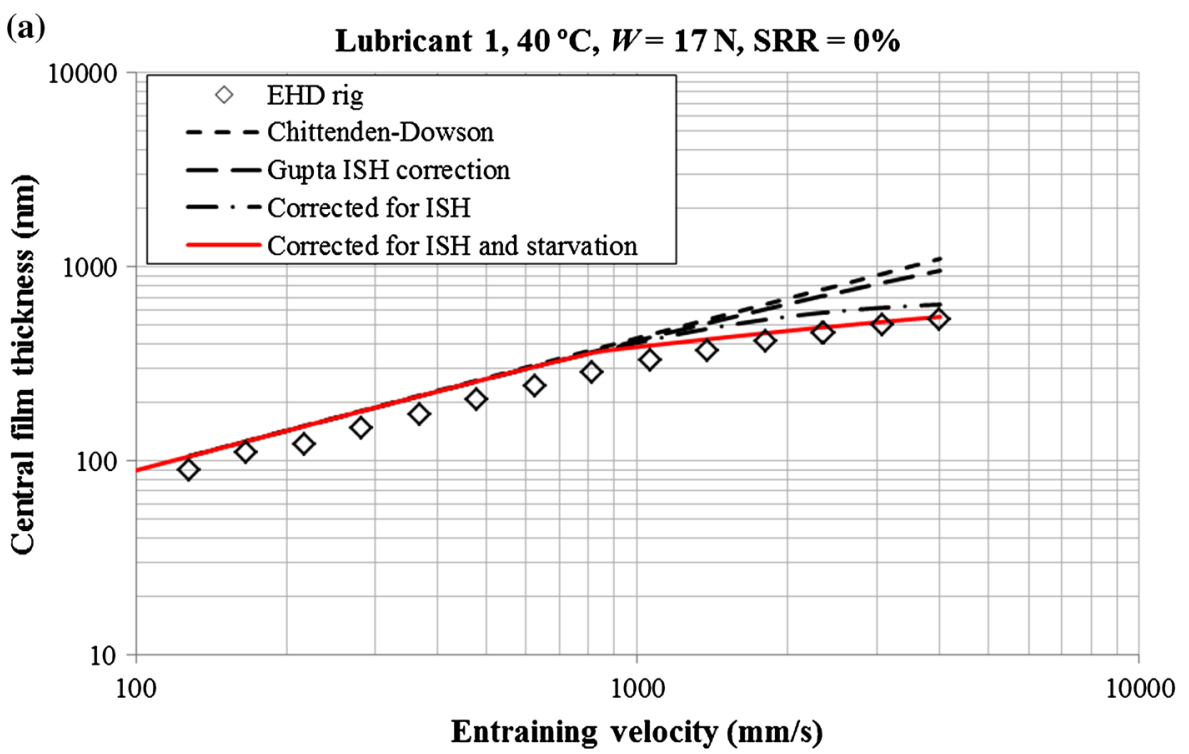

(b) Lubricant $2,40^{\circ} \mathrm{C}, W=17 \mathrm{~N}, \mathrm{SRR}=0 \%$

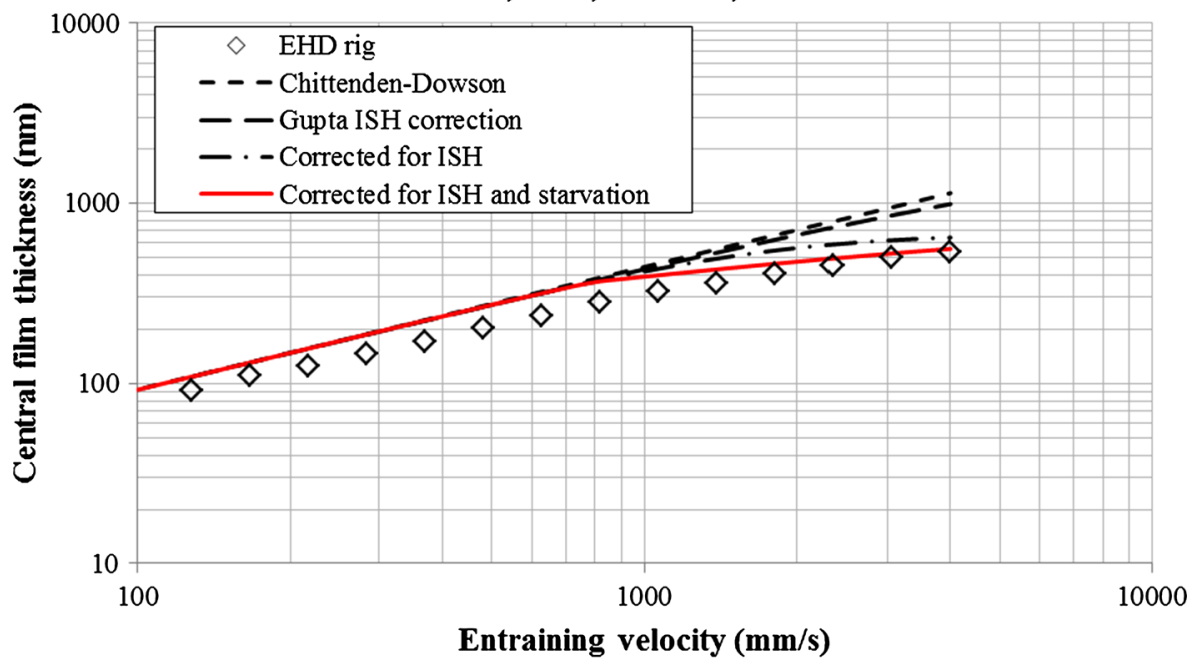

(c) Lubricant $3,40^{\circ} \mathrm{C}, W=17 \mathrm{~N}, \mathrm{SRR}=0 \%$

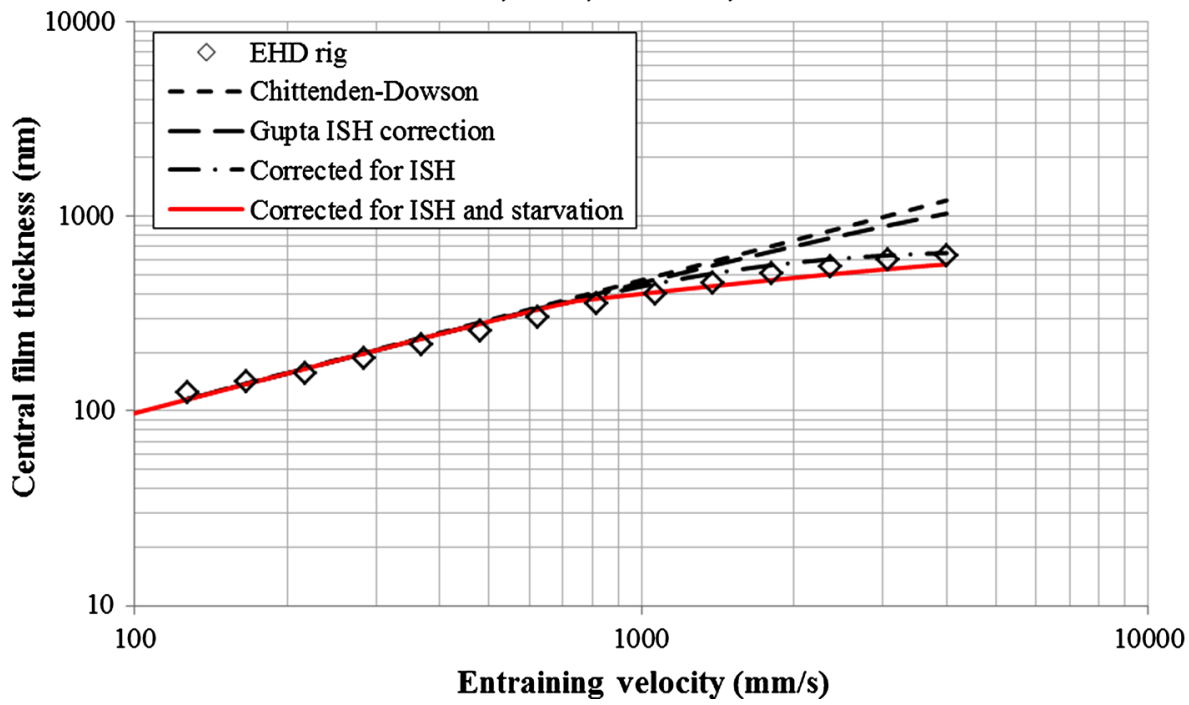




\subsection{Film Thickness}

The inlet zone analysis does not account for the effect of inlet shear thinning, since Newtonian inlet shear is assumed. Figure $6 \mathrm{a}-\mathrm{c}$ shows the central oil film thickness measurements, as well as the corresponding predictions for the examined lubricants. The conditions used are $W=17 \mathrm{~N}$ and SRR $=0 \%$ (pure rolling). Also note that: $E^{\prime}=116.9 \mathrm{GPa}$ (for steel against glass). The oil bath temperature was maintained at $40{ }^{\circ} \mathrm{C}$ in order to better demonstrate the impact of ISH and starvation upon central contact oil film thickness.

Good agreement is found between the predictions and measurements for all the examined lubricants. With an increasing rolling velocity, the predictions from Chittenden-Dowson equation [30] deviate from the experimental measurements. Nevertheless, the model predictions follow the same trend as the experimental measurements. When the speed of entraining motion exceeds $1 \mathrm{~m} / \mathrm{s}$, excluding the effects of ISH and starvation tends to a significant overestimation of the central contact oil film thickness. Applying the correction factor of Gupta et al. [39] without the inclusion of the starvation phenomena also tends to overestimate the central oil film thickness. Figure 6 shows this trend.

The inlet temperature with the increased entraining velocity is shown in Fig. 7. The decrease in the inlet temperature rise with increasing oil bath temperature is also well known. With starvation, the predicted inlet temperature rise deviates from that under fully flooded inlet condition. There are clearly a reduced volume of lubricant under shear in a starved contact and thus a decrease in the inlet temperature rise. The inlet temperature rise is proportional to $h_{\mathrm{c}}^{4}$ (Eq. 18), and thus a reduction in the central oil film thickness can also result in a significant fall in the inlet temperature. The plots demonstrated in Fig. 7 suggest that ISH and starvation are two mechanisms which strongly interact, although somewhat different in nature. The extent of ISH depends on the central oil film thickness, affected by starvation, which in turn depends on the ISH. Starvation is a function of lubricant flow number, which in turn depends on the inlet viscosity and consequently on the extent of ISH. The natural outcome of the above observation is to state that ISH and starvation do not act independently, but they are rather strongly coupled.

\subsection{EHD Friction}

Figure 8a-c shows the variation of the EHD coefficient of friction with the SRR. The loading and the speed conditions are the same as those of the MTM $(W=20 \mathrm{~N}$ and $=$ $2.5 \mathrm{~m} / \mathrm{s}$ ). In addition, the temperature of the oil bath was maintained at $40^{\circ} \mathrm{C}$. Experimentally measured and numerically predicted coefficients of friction are compared. The coefficient of friction is predicted by assuming five different conditions, including Newtonian isothermal, nonNewtonian isothermal, non-Newtonian thermal with and without the effect of ISH and non-Newtonian thermal without ISH, but with the effect of starvation. The purpose of these is to investigate the importance of each set of assumptions on the accuracy of the predicted results, thus highlighting the influence of each mechanism on the EHD friction, as well as their interactions.

As expected an overestimation of coefficient of friction occurs with the Newtonian isothermal model. This is apparent for all the three examined lubricants. However, when the shear thinning effect, along with the concept of limiting shear stress, is taken into account, the predictions
Fig. 7 Inlet temperature rise in the optical interferometry rig
Lubricant $1, S R R=0, W=17 \mathrm{~N}$

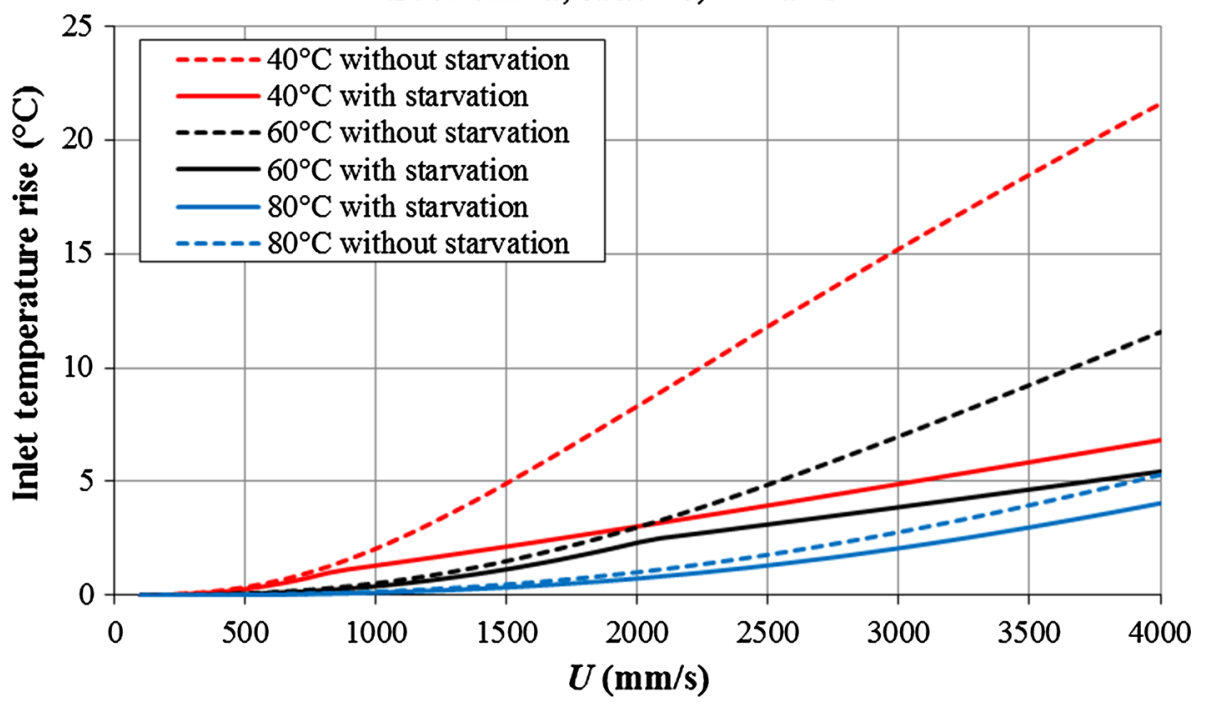


Fig. 8 Coefficient of friction for a lubricant 1 , b lubricant 2 and c lubricant 3 at $40{ }^{\circ} \mathrm{C}$
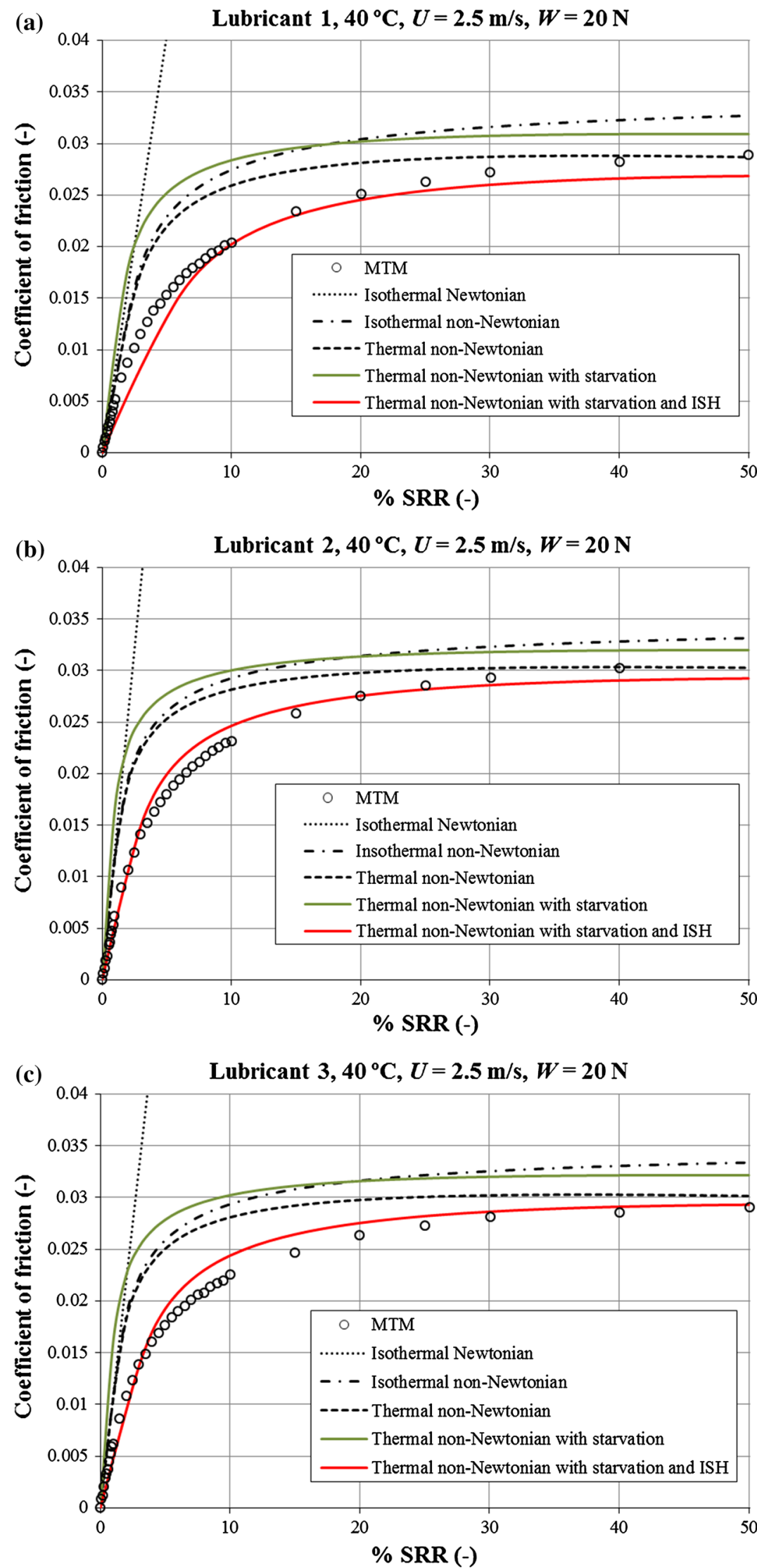
are significantly improved. When the shear heating at the centre of the conjunction is included, good agreement with the experimental results is observed for higher SRR values. However, for lower SRR values, the thermal friction model tends to somewhat overestimate the coefficient of friction. This observation suggests the possible occurrence of other friction reduction mechanisms, which are not taken account for in the analyses. It is suggested that at least one mechanism is shear heating at the inlet conjunction. Inclusion of this phenomenon in the analysis demonstrates improved agreement with the measurements. Achieving a better conformance with measurements is only possible when the inlet temperature rise is known, which is entirely possible by simply applying a thermal correction coefficient when calculating the central lubricant film thickness. Therefore, the better noted agreement is due to the effective estimation of the lubricant inlet viscosity using the current analytical model. For low-to-moderate SRR values, the predictions from the EHD friction model, taking into account the ISH phenomenon, highlight the importance of including the ISH in the predictive thermal EHD models.

Figure 8a-c also shows that ISH reduces EHD traction with increasing SRR. However, it should be noted that shear thinning may counteract this beneficial effect. Therefore, future inclusion of shear thinning in such analyses would be essential, as shear thinning sets a limit on the traction of EHD films as has been shown by disc machine experiments, for example leading to scuffing failures [50]. Figure 9 shows that the rise in the average central contact temperature increases with SRR. For pure rolling $(\mathrm{SRR}=0 \%)$, the average central contact temperature rise is equal to the inlet temperature rise due to the ISH effect (i.e. negligible rise in contact temperature under pure rolling condition [50]). Hence, for low SRR, the observed central temperature rise is as a direct consequence of the temperature rise at the inlet conjunction. The viscosity of the lubricant entering the conjunction is already reduced at the inlet, when compared with the bulk lubricant viscosity, and hence the reduction in EHD friction when taking ISH into account even under pure rolling conditions. As SRR increases, further shear heating in the central region of the conjunction occurs (Fig. 9), and thus the dependence of EHD friction on ISH alone is less pronounced. With regard to the contribution of the starvation to the EHD coefficient of friction, two important and interdependent observations can be made. Firstly, it is noted that the friction model for the case of the thermal non-Newtonian with ISH yields an almost identical coefficient of friction with or without the effect of starvation (therefore, only one curve is plotted for these cases in Fig. 10a-c). This shows that with ISH, the inlet viscosity drops, reducing the lubricant flow number, and in effect causes starvation itself. Secondly, under non-Newtonian thermal conditions without ISH and only accounting for lubricant starvation the coefficient of friction is overestimated, compared with a fully flooded inlet, which would be contrary to expectations. This is because without ISH the lubricant flow number remains sufficiently high to give rise to starvation, and thus an underestimation of the central oil film thickness occurs, leading to an overestimation of the coefficient of friction. Summarising the above findings, it is suggested that, in addition to the central film thickness, the interaction of ISH and starvation mechanisms can have significant contributions to the EHD friction.

Equation (19) suggests that the inlet temperature rise should decline if the viscosity of the lubricant at the inlet conjunction reduces, since $\Delta T_{\mathrm{i}} \sim \eta_{0}\left(p_{\mathrm{a}}, T_{i}\right)^{1.72}$. This leads to the conclusion that when the temperature of the bulk
Fig. 9 Average temperature rise at the centre of the contact calculated for different SRR values for several oil bath temperatures (note that the curves for lubricants 1 and 2 coincide)

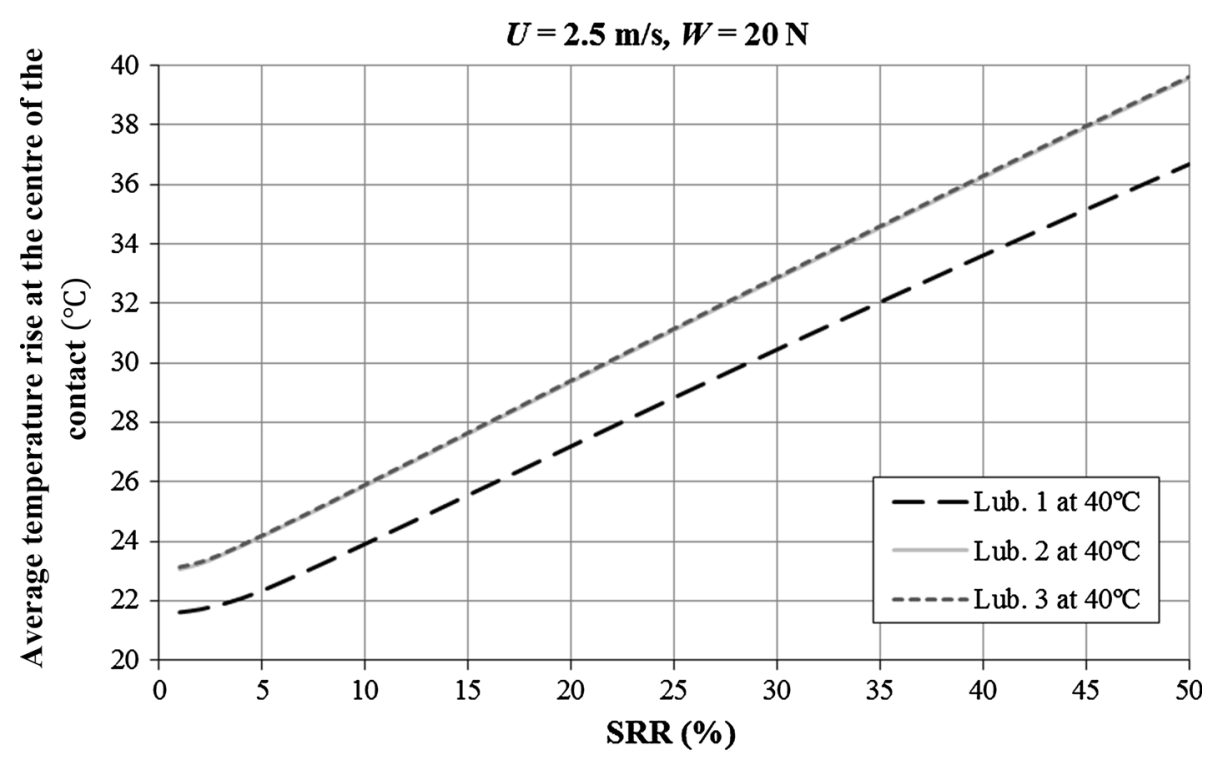


Fig. 10 Coefficient of friction for lubricant 1 at a $60{ }^{\circ} \mathrm{C}$ and b $80{ }^{\circ} \mathrm{C}$
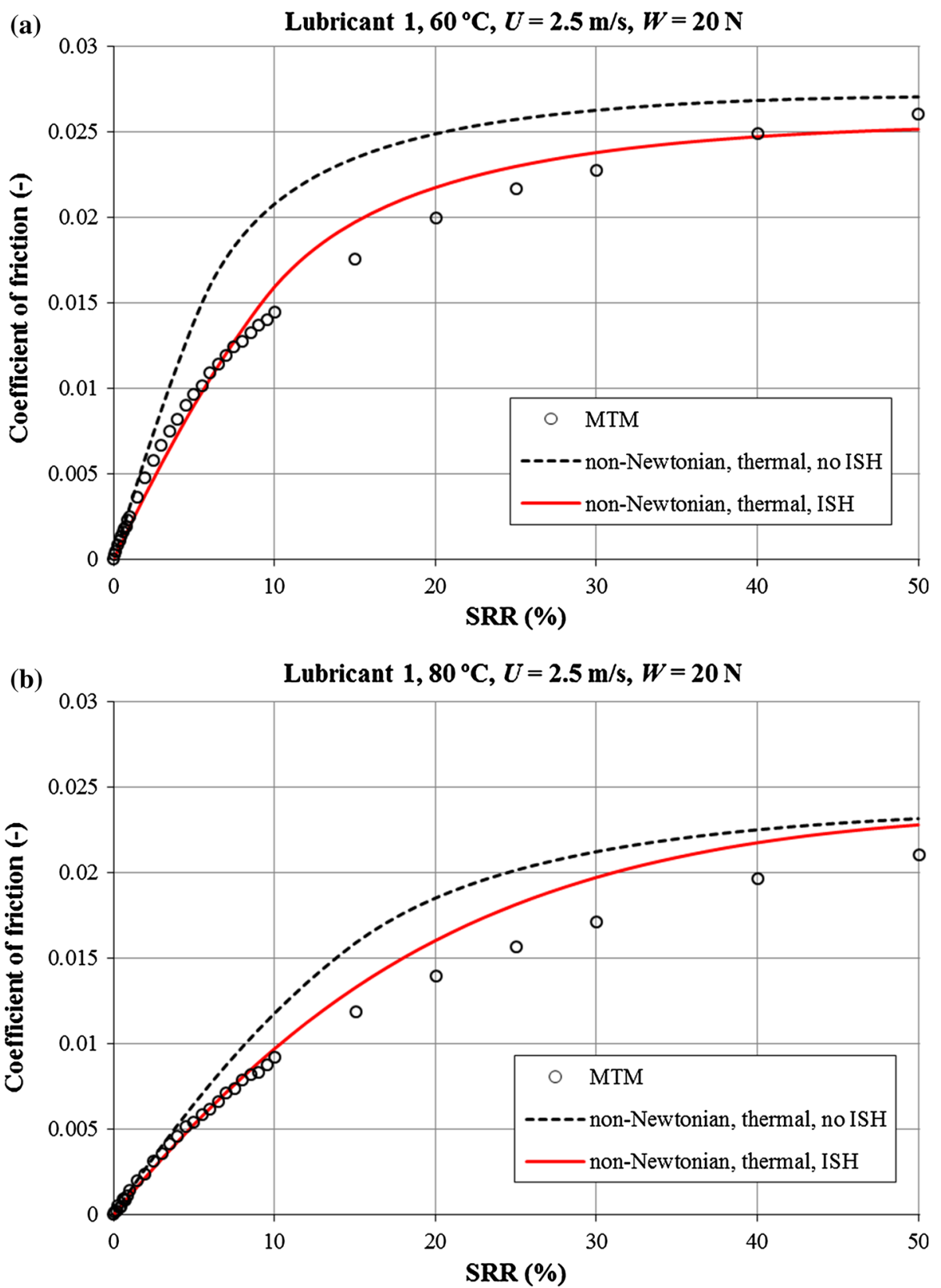

lubricant (bath temperature) increases, inlet shear heating and thus the inlet temperature rise would decrease.

Figure $10 \mathrm{a}-\mathrm{b}$ is for lubricant 1 at two different oil bath temperatures of 60 and $80{ }^{\circ} \mathrm{C}$, which shows good agreement between the predictions and the measured data, indicating that the main mechanisms affecting EHD contact friction are accounted for in the presented model. The deviation between the predicted and measured data at the bath oil temperature of $T_{b}=80^{\circ} \mathrm{C}$ is only $10 \%$ (see Fig. 10b). It is also noteworthy that the lubricant flow number, under the conditions in Fig. $8 \mathrm{a}-\mathrm{c}$, is below $2 \times 10^{-7}$. Consequently, the effect of starvation is only partial (fully flooded contact).

Figure 10a, b shows that with an increasing bath oil temperature, the models with and without the effect of ISH tend to agree well throughout the examined range of SRR values (from pure rolling up to moderate sliding). This is because of the effect of ISH, and hence, its impact upon EHD traction reduces as the bulk oil temperature rises. Further evidence for this is provided by examining the variation of the average central temperature rise of lubricant 1 with SRR at three different bath oil temperatures as shown in Fig. 11. The inlet temperature rise drops significantly with an increasing bath temperature (this is identical to the average central temperature rise under pure rolling condition).

Finally, Fig. 12a, b illustrates the variation of coefficient of friction with SRR for lubricants 2 and 3 at 60 and $80{ }^{\circ} \mathrm{C}$. The coefficient of friction is determined through the use of MTM at $W=20 \mathrm{~N}$ and $U=2.5 \mathrm{~m} / \mathrm{s}$. 
Fig. 11 Average central temperature rise for lubricant 1

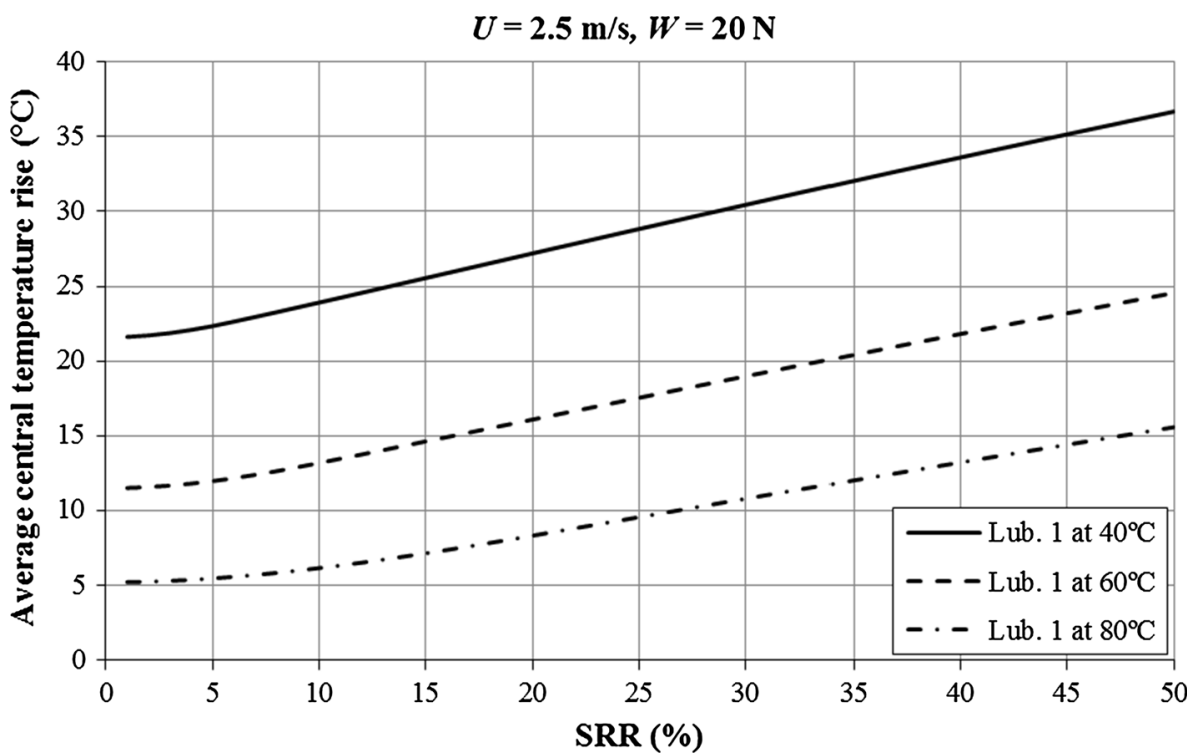

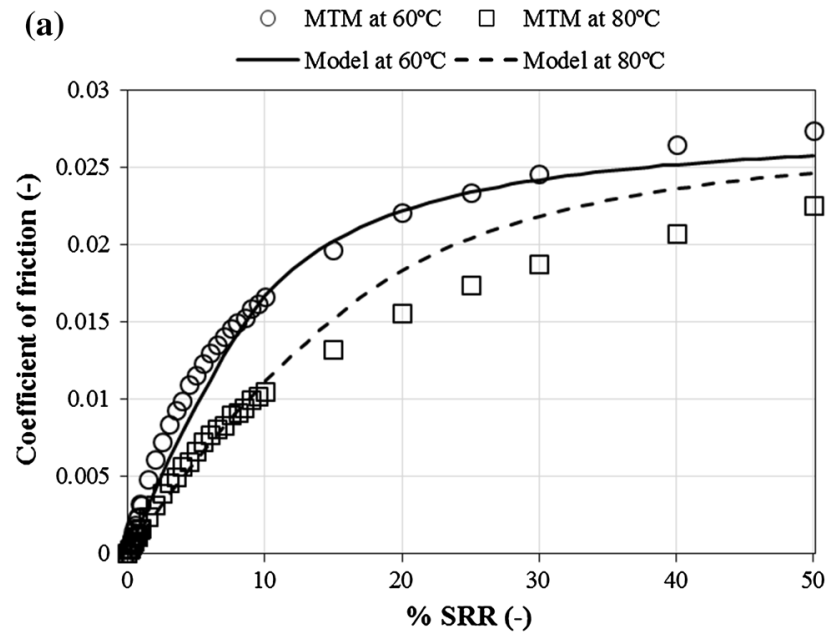

(b)

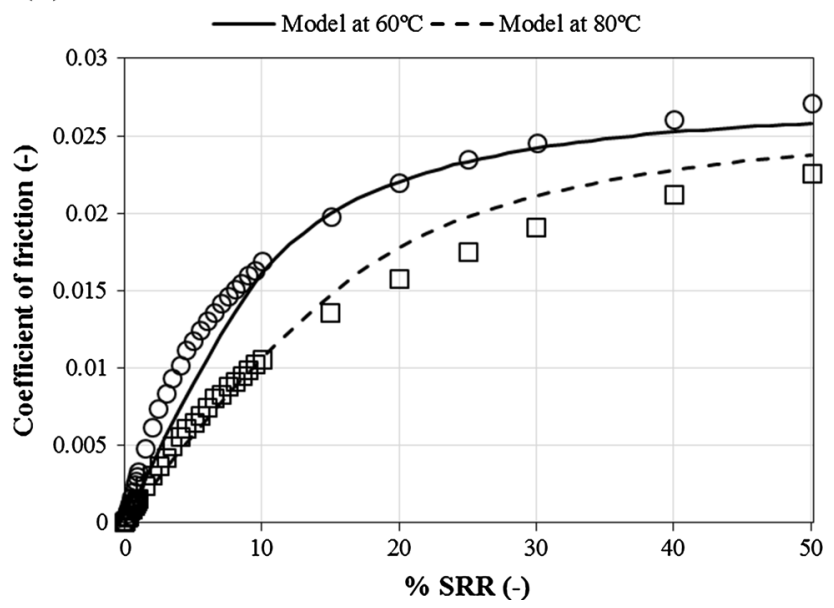

Fig. 12 Coefficient of friction for a lubricant 2 and $\mathbf{b}$ lubricant 3 at 60 and $80{ }^{\circ} \mathrm{C}(\mathrm{MTM}$ at $W=20 \mathrm{~N}$ and $=2.5 \mathrm{~m} / \mathrm{s}$ )
As it is shown in Fig. 12a, b, the predictions of the friction model, accounting for both the effects of ISH and starvation, are in good agreement with the measured coefficient of friction. A slight overestimation of the coefficient of friction is observed for both lubricants at $80^{\circ} \mathrm{C}$ which can be attributed to the reduction in the limiting shear stress-pressure proportionality coefficient $\gamma_{L}$ with the temperature [32] which has not been taken into account in the current study.

\section{Conclusions}

An analytical EHD friction model is presented and its findings validated through measurement of friction using an MTM, as well as lubricant film thickness using optical interferometry. Three fully formulated PAO SAE 75W-90 transmission lubricants, blended with different types of VMs, are fully characterised in terms of understanding their high-shear and high-pressure viscosity behaviour. Effects such as the temperature rise at the central region of the conjunction as well as the effect of inlet shear heating (ISH) and contact starvation are also investigated. The effect of the limiting shear stress is also accounted for. Good agreement is found between the measured film thickness/coefficient of friction and the corresponding predictions of the model, indicating that the employed method can discriminate between the tribological performance of lubricants of the same viscosity grade but with different VMs.

It is shown that the developed model can discriminate between lubricants with different additive packs. The main conclusions are:

- The inlet temperature rise due to inlet shear can have a profound effect upon accurate prediction of coefficient of friction, especially at lower SRR values. 
- When the SRR is kept relatively low, shear heating in the central region of the conjunction tends to be lower than that at the inlet. Hence, reduction in viscosity at the centre of the EHD conjunction due to thermal effects is mainly driven by the ISH action. With increasing SRR, shear heating at the centre of the conjunction dominates the ISH effect.

- The effect of ISH on the EHD traction is more pronounced for lower bulk (bath) oil temperatures. As a result, the effect of ISH is somewhat exaggerated.

- The performed inlet zone analysis reveals that there is an inverse relationship between the magnitude of the reciprocal asymptotic iso-viscous PV coefficient and the inlet temperature rise, particularly at relatively low values of SRR.

- The ISH and starvation interact following a rather simple mechanism. Due to ISH, the inlet viscosity drops, leading to a reduced lubricant flow number. Hence, the effect of starvation is somewhat mitigated.

- Inlet shear heating and starvation affect the viscous coefficient of friction, as well as the EHD film thickness.

Acknowledgments The authors would like to express their gratitude to Lubrizol Ltd. for sponsorship of this research. Special thanks are due to Dr. Farrukh Qureshi (Lubrizol Corporation., Wickliffe, Ohio) for providing the high-pressure viscosity data and to Dr. Eugene Pashkovski (Lubrizol Corporation., Wickliffe, Ohio) for providing the high-shear-rate viscosity data.

Open Access This article is distributed under the terms of the Creative Commons Attribution 4.0 International License (http://creative commons.org/licenses/by/4.0/), which permits unrestricted use, distribution, and reproduction in any medium, provided you give appropriate credit to the original author(s) and the source, provide a link to the Creative Commons license, and indicate if changes were made.

\section{Appendix 1}

The energy equation for the inlet zone is given by Eq. (16) Greenwood and Kauzlarich [9]. Integrating twice across the film thickness yields:

$T_{\mathrm{i}}\left(-r_{\mathrm{h}}, z\right)=-\frac{z^{4}}{12 k_{f} \eta_{0}\left(p_{\mathrm{a}}, T_{\mathrm{i}}\right)}\left(\left.\frac{\partial p}{\partial x}\right|_{x=-r_{\mathrm{h}}}\right)^{2}+c_{1} z+c_{2}$

The integration constants $c_{1}$ and $c_{2}$ are determined by setting $T_{\mathrm{i}}\left(-r_{\mathrm{h}}, 0\right)=T_{\mathrm{b}}$ and $T_{\mathrm{i}}\left(-r_{\mathrm{h}}, h_{\mathrm{c}}\right)=T_{\mathrm{b}}$, yielding:

$$
\begin{aligned}
T_{\mathrm{i}}\left(-r_{\mathrm{h}}, z\right)= & -\frac{z^{4}}{12 k_{f} \eta_{0}\left(p_{\mathrm{a}}, T_{\mathrm{i}}\right)}\left(\left.\frac{\partial p}{\partial x}\right|_{x=-r_{\mathrm{h}}}\right)^{2} \\
& +\frac{h_{\mathrm{c}}^{3}}{12 k_{f} \eta_{0}\left(p_{\mathrm{a}}, T_{\mathrm{i}}\right)}\left(\left.\frac{\partial p}{\partial x}\right|_{x=-r_{\mathrm{h}}}\right)^{2} z+T_{\mathrm{b}}
\end{aligned}
$$

The inlet temperature is considered at the centre of the distance between the adjacent solids. Hence, $T_{\mathrm{i}}=T_{\mathrm{i}}$ $\left(-r_{\mathrm{h}}, h_{\mathrm{c}} / 2\right)$. Setting $\Delta T_{\mathrm{i}}=T_{\mathrm{i}}-T_{\mathrm{b}}$ and substituting into Eq. (35) yields:

$$
\begin{aligned}
\Delta T_{\mathrm{i}}= & -\frac{h_{\mathrm{c}}^{4}}{192 k_{f} \eta_{0}\left(p_{\mathrm{a}}, T_{\mathrm{i}}\right)}\left(\left.\frac{\partial p}{\partial x}\right|_{x=-r_{\mathrm{h}}}\right)^{2} \\
& +\frac{h_{\mathrm{c}}^{4}}{12 k_{f} \eta_{0}\left(p_{\mathrm{a}}, T_{\mathrm{i}}\right)}\left(\left.\frac{\partial p}{\partial x}\right|_{x=-r_{\mathrm{h}}}\right)^{2}
\end{aligned}
$$

Rearranging Eq. (36) yields Eq. (19).

\section{Appendix 2}

The polynomial coefficients in Eq. (24) are provided in this appendix. These are determined through regression in the form of a fourth-order polynomial expression to the corrective function $L_{\mathrm{cor}}$. This is determined at discrete points, corresponding to the experimentally determined values provided in [41]. Initially, Eq. (23) is fitted to the experimental data, assuming that $L_{\mathrm{cor}}=1$. The magnitude of the corrective function is then evaluated at all discrete points with minimum squared deviation between the predicted film reduction coefficient and the corresponding experimental measurement. Table 4 lists these polynomial coefficients.

Table 4 Polynomial coefficients used in Eq. 24

\begin{tabular}{lll}
\hline Polynomial coefficient & $G \cdot U_{e}<6 \times 10^{-7}$ & $G \cdot U_{e} \geq 6 \times 10^{-7}$ \\
\hline$a_{1}$ & $1.917 \times 10^{25}$ & $-1.151 \times 10^{16}$ \\
$a_{2}$ & $-3.811 \times 10^{19}$ & $2.416 \times 10^{12}$ \\
$a_{3}$ & $2.822 \times 10^{13}$ & $-1.913 \times 10^{8}$ \\
$a_{4}$ & $-9.342 \times 10^{6}$ & $7.395 \times 10^{3}$ \\
$a_{5}$ & 2.139 & 0.933 \\
\hline
\end{tabular}

\section{References}

1. Dowson, D., Higginson, G.R.: Elasto-hydrodynamic Lubrication. Pergamon Press, UK (1977)

2. Gohar, R., Rahnejat, H.: Fundamentals of Tribology. Imperial College Press, London (2008)

3. Hamrock, B.J., Dowson, D.: Isothermal elastohydrodynamic lubrication of point contacts (Part I-theoretical formulation). Trans ASME J. Lubr. Tech. 98, 223-228 (1976)

4. Chittenden, R.J., Dowson, D., Dunn, J.F., Taylor, C.M.: A theoretical analysis of the isothermal elastohydrodynamic lubrication of concentrated contacts-I. Direction of lubricant entrainment coincident with the major axis of the Hertzian contact ellipse. Proc. R. Soc. Ser. A Math. Phys. Eng. Sci. 397, 245-269 (1985)

5. Venner, C.H., Napel, W.E.T.: Multilevel solution of the elastohydrodynamically lubricated circular contact problem Part I: theory and numerical algorithm. Wear 152, 351-367 (1992) 
6. Nijenbanning, G., Venner, C.H., Moes, H.: Film thickness in elastohydrodynamically lubricated elliptic contacts. Wear 176, 217-229 (1994)

7. Habchi, W., Bair, S., Qureshi, F., Covitch, M.: A film thickness correction formula for double-newtonian shear-thinning in rolling EHL circular contacts. Tribol. Lett. 50, 59-66 (2012)

8. Crook, A.W.: The lubrication of rollers. Philos. Trans. R. Soc. Ser. A Math. Phys. Eng. Sci. 250, 387-409 (1958)

9. Greenwood, J.A., Kauzlarich, J.J.: Inlet shear heating in elastohydrodynamic lubrication. Trans. ASME J. Lubr. Tech. 95(4), 417-423 (1973)

10. Dyson, A., Wilson, A.R.: Film thicknesses in elastohydrodynamic lubrication by silicone fluids. Proc. IMechE 180, 97-112 (1965)

11. Hargreaves, R.A., Higginson, G.R.: Some effects of lubricant starvation in cylindrical roller bearings. Trans. ASME J. Lubr. Tech. 98(1), 66-71 (1976)

12. Chiu, Y.P.: An analysis and prediction of lubricant film starvation in rolling contact systems. Trans. ASLE 17, 22-35 (1974)

13. Tipei, N.: Boundary conditions of a viscous flow between surfaces with rolling and sliding motion. Trans. ASME J. Lubr. Tech. 90(1), 254-261 (1968)

14. Mohammadpour, M., Johns-Rahnejat, P.M., Rahnejat, H., Gohar, R.: Boundary conditions for elastohydrodynamics of circular point contacts. Tribol. Lett. 53, 107-118 (2013)

15. Crook, A.W.: The lubrication of rollers, III. A theoretical discussion of friction and the temperatures in the oil film. Proc. R. Soc. Lond. Ser. A 254, 237-258 (1961)

16. Crook, A.W.: The lubrication of rollers IV. Measurements of friction and effective viscosity. Philos. Trans. R. Soc. A Math. Phys. Eng. Sci. 255, 281-312 (1963)

17. Plint, M.A.: Traction in elastohydrodynamic contacts. Proc. IMechE 182, 300-306 (1967)

18. Johnson, K.L., Cameron, R.: Shear behaviour of elastohydrodynamic oil films at high rolling contact pressures. Proc. IMechE 182(1), 307-330 (1967)

19. Hirst, W., Moore, A.J.: Non-Newtonian behaviour in elastohydrodynamic lubrication. Proc. R. Soc. Ser. A Math. Phys. Eng. Sci. 337, 101-121 (1974)

20. Johnson, K.L., Tevaarwerk, J.L.: Shear behaviour of elastohydrodynamic oil films. Proc. R. Soc. Ser. A Math. Phys. Eng. Sci. 356, 215-236 (1977)

21. Ree, T., Eyring, H.: Theory of non-Newtonian flow. I. Solid plastic system. J. Appl. Phys. 26, 793-800 (1955)

22. Karagiannis, I., Theodossiades, S., Rahnejat, H.: On the dynamics of lubricated hypoid gears. Mech. Mach. Theory 48, 94-120 (2012)

23. Mohammadpour, M., Theodossiades, S., Rahnejat, H., Saunders, T.: Non-Newtonian mixed elastohydrodynamics of differential hypoid gears at high loads. Meccanica 49, 1115-1138 (2013)

24. Bair, S., Winer, W.O.: A rheological model for elastohydrodynamic contacts based on primary laboratory data. Trans. ASME J. Tribol. 101, 258-264 (1979)

25. Bair, S.: Elastohydrodynamic film forming with shear thinning liquids. Trans. ASME J. Tribol. 120, 173-178 (1998)

26. Bair, S.: A critical assessment of the role of viscometers in quantitative elastohydrodynamics. Tribol. Trans. 55, 394-399 (2012)

27. Carreau, P.J., De Kee, D.C.R., Chhabra, R.P.: Rheology of polymeric systems. Hanser Verlag, Munich (1997)

28. Bair, S., Vergne, P., Querry, M.: A unified shear-thinning treatment of both film thickness and traction in EHD. Tribol. Lett. 18, 145-152 (2005)

29. Liu, Y., Wang, Q.J., Bair, S., Vergne, P.: A quantitative solution for the full shear-thinning EHL point contact problem including traction. Tribol. Lett. 28, 171-181 (2007)
30. Chittenden, R.J., Dowson, D., Dunn, J.F., Taylor, C.M.: A theoretical analysis of the isothermal elastohydrodynamic lubrication of concentrated contacts. II. General case, with lubricant entrainment along either principal axis of the Hertzian contact ellipse or at some intermediate angle. Proc. R. Soc. Ser. A Math. Phys. Eng. Sci. 397, 271-294 (1985)

31. Spikes, H., Jie, Z.: History, origins and prediction of elastohydrodynamic friction. Tribol. Lett. 56(1), 1-25 (2014)

32. Hoglund, E., Jacobson, B.: Experimental investigation of the shear strength of lubricants subjected to high pressure and temperature. Trans. ASME J. Tribol. 108, 571-577 (1986)

33. Ståhl, J., Jacobson, B.O.: A non-Newtonian model based on limiting shear stress and slip planes-parametric studies. Tribol. Int. 36, 801-806 (2003)

34. Olver, A.V.: Testing transmission lubricants: the importance of thermal response. Proc. IMechE, Part G J. Aerosp. Eng. 205, 35-44 (1991)

35. Morris, N., Rahmani, R., Rahnejat, H., King, P.D., Fitzsimons, B.: Tribology of piston compression ring conjunction under transient thermal mixed regime of lubrication. Tribol. Int. 59, 248-258 (2013)

36. Olver, A.V., Spikes, H.A.: Prediction of traction in elastohydrodynamic lubrication. Proc. IMechE Part J J. Eng. Tribol. 212, 321-332 (1998)

37. Grubin, A.N., Vinogradova, I.: Fundamentals of the hydrodynamic lubrication of heavily loaded cylindrical surfaces. Book B., No. 30, Cent. Sci. Res. Inst. Technol. Mech. Eng. DSIR, Moscow (1949)

38. Cameron, A.: Principles of Lubrication. Longman Press, London (1966)

39. Gupta, P.K., Cheng, H.S., Zhu, D., Forster, N.H., Schrand, J.B.: Viscoelastic effects in MIL-L-7808-type lubricant, Part I: analytical formulation. Tribol. Trans. 35, 269-274 (2008)

40. Hamrock, B.J., Dowson, D.: Isothermal elastohydrodynamic lubrication of point contacts Part IV-Starvation results. Trans. ASME J. Lubr. Tech. 99(1), 15-23 (1977)

41. Zaretsky, E.: Bearing elastohydrodynamic lubrication: a complex calculation made simple. NASA Tech. Memo. 102575 (1990)

42. Bair, S., Liu, Y., Wang, Q.J.: The pressure-viscosity coefficient for Newtonian EHL film thickness with general piezoviscous response. Trans. ASME J. Tribol. 128, 624-631 (2006)

43. Bair, S.: An experimental verification of the significance of the reciprocal asymptotic isoviscous pressure for EHD lubricants. Tribol. Trans. 36, 153-162 (1993)

44. Roelands, C.: Correlational Aspects of the Viscosity-Temperature Pressure Relationship of Lubricating Oils. Ph.D. Thesis, Delft University of Technology (1966)

45. Houpert, L.: New results of traction force calculations in elastohydrodynamic contacts. Trans. ASME J. Tribol. 107, 241-248 (1985)

46. Williams, M.L., Landel, R.F., Ferry, J.D.: The temperature dependence of relaxation mechanisms in amorphous polymers and other glass-forming liquids. J. Am. Chem. Soc. 77, 3701-3707 (1955)

47. Havriliak, S., Negami, S.: A complex plane representation of dielectric and mechanical relaxation processes in some polymers. Polymer 8, 161-210 (1967)

48. Bair, S., Qureshi, F.: Time-temperature-pressure superposition in polymer thickened liquid lubricants. Trans. ASME J. Tribol. 136(2), 1-6 (2014)

49. Gohar, R.: Elastohydrodynamics, 2nd edn. Imperial College Press, London (2001)

50. Macpherson, P.B.: Lubrication in Gear Scuffing and Pitting. Ph.D. thesis, Imperial College, Univercity of London (1972)

51. Paouris, L., Theodossiades S., De la Cruz, M., Rahnejat, H., Kidson, A., Hunt, G., Barton, W.: Lubrication analysis and subsurface stress field of an automotive differential hypoid gear pair under dynamic loading. IMechE J. Mech. Eng. Sci. 1-15 (2015) 